\title{
Treatment of Biomass
}

Gasification Wastewater Using a Combined Wet Air Oxidation/ Activated Sludge Process
C. J. English
S. E. Petty
D. S. Sklarew

February 1983

Prepared for the U.S. Department of Energy under Contract DE-AC06-76RLO 1830

Pacific Northwest Laboratory Operated for the U.S. Department of Energy by Battelle Memorial Institute 


\title{
DISCLAIMER
}

This report was prepared as an account of work sponsored by an agency of the United States Government. Neither the United States Government nor any agency thereof, nor any of their employees, makes any warranty, express or implied, or assumes any legal liability or responsibility for the accuracy, completeness, or usefulness of any information, apparatus, product, or process disclosed, or represents that its use would not infringe privately owned rights. Reference herein to any specific commercial product, process, or service by trade name, trademark, manufacturer, or otherwise, does not necessarily constitute or imply its endorsement, recommendation, or favoring by the United States Government or any agency thereof. The views and opinions of authors expressed herein do not necessarily state or reflect those of the United States Government or any agency thereof.

\author{
PACIFIC NORTHWEST LABORATORY \\ operated by \\ BATTELLE \\ for the \\ UNITED STATES DEPARTMENT OF ENERGY \\ under Contract DE-AC06-76RLO 1830
}

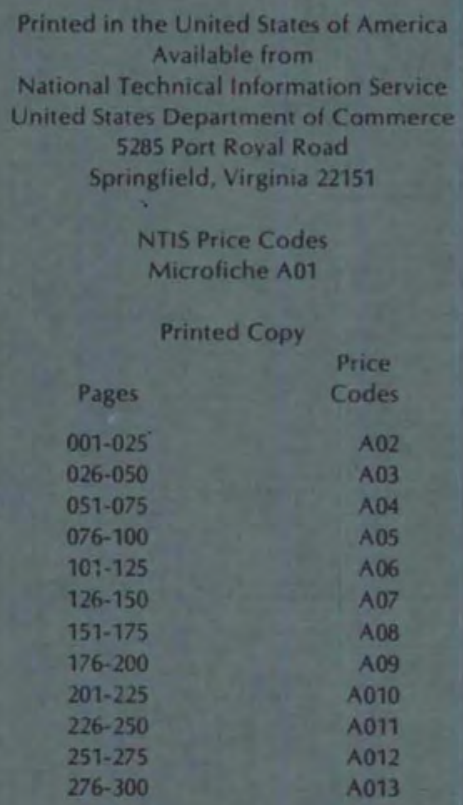


TREATMENT OF BIOMASS GASIFICATION WASTEWATER USING A COMBINED WET

AIR OXIDATION/ACTIVATED

SLUDGE PROCESS

\author{
C. J. English \\ S. E. Petty \\ D. S. Sklarew
}

February 1983

Prepared for the U.S. Department of Energy under Contract DE-AC06-76RLO 1830

Pacific Northwest Laboratory Richland, Washington 99352 


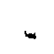




\section{PREFACE}

This report is one of a series prepared by Pacific Northwest Laboratory for the U.S. Department of Energy on treatment of biomass gasification wastewaters. Other reports have dealt with biological treatment, carbon adsorption, chemical precipitation, reverse osmosis, solvent extraction, and wet air oxidation. All the reports include results of experimental work on a laboratory scale. Wastewater used in these studies came from the experimental Synthesis Gas From Manure (SGFM) biomass gasifier at Texas Tech University. 


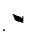

$-$ 


\section{ACKNOWLEDGMENTS}

The authors wish to acknowledge the efforts of the following PNL staff who assisted in performing the experiments described in this report:

- Marie Laegreid, who maintained the biological reactors and performed wet chemical analyses;

- Pete Swift, who operated the autoclave used to oxidize the wastewater; and

- Randy Pahl and Sylvia Downey, who performed GC and GC/MS analyses.

We also wish to acknowledge Dr. Steven Beck, of Texas Tech University, who furnished the wastewater samples used in this study.

Funding was provided by the U.S. Department of Energy through Argonne National Laboratory. 


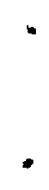




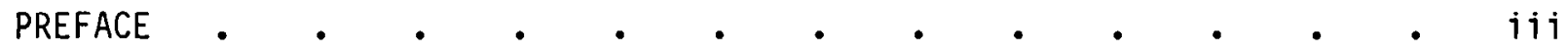

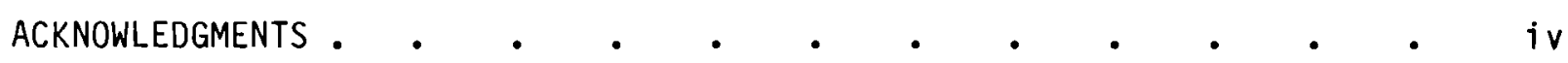

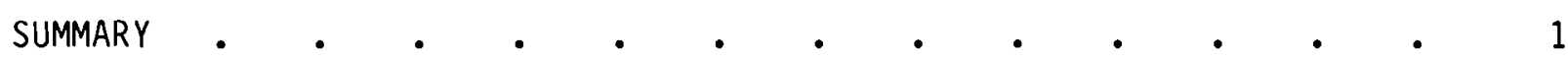

CONCLUSIONS $\quad$ • $\quad$ • $\quad$ •

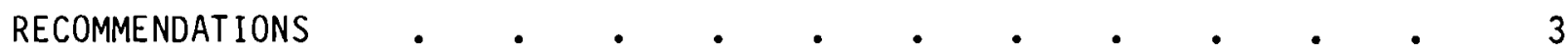

INTRODUCTION

BACKGROUND $•$ •

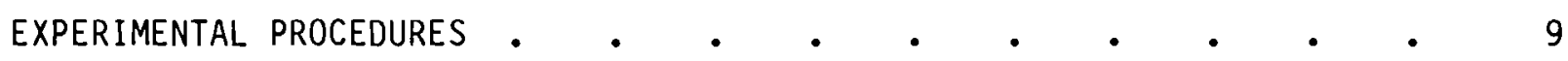

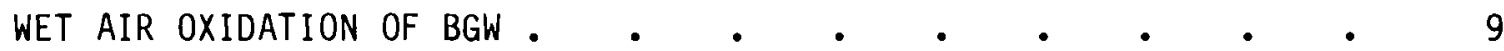

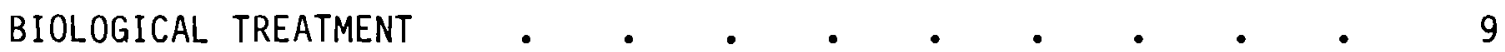

DETERMINATION OF VOLATILE COD LOSSES $\quad$ • $\quad$ • $\quad$ • $\quad$ • $\quad$ • $\quad$ • 14

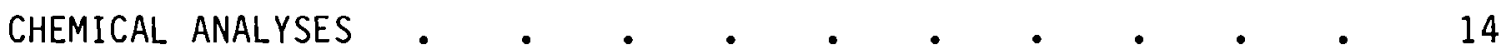

RESULTS •

WET AIR OXIDATION $\quad$ • $\quad$ • $\quad$ •

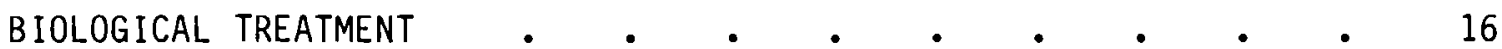

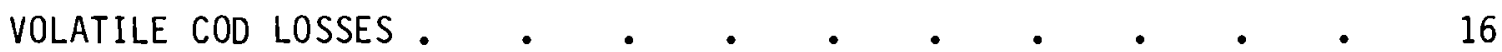

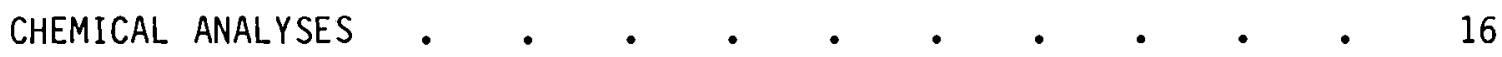

DISCUSSION

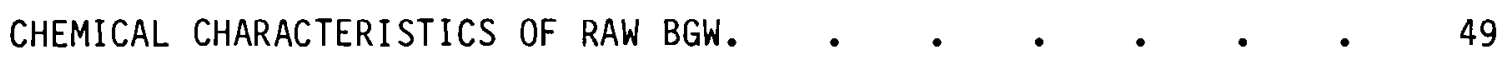

WET AIR OXIDATION

BIOLOGICAL TREATMENT $\quad$ • . . . . . . . . . . 50

Composition of Effluent . . . . . . . . 50

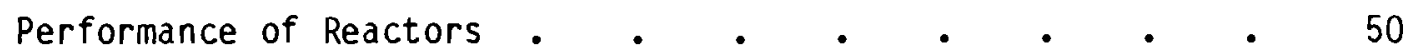

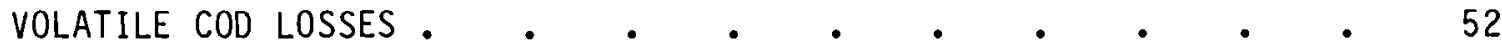

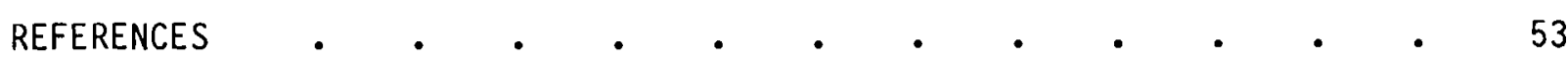




\section{FIGURES}

1 Laboratory Scale Wet Air 0xidation Apparatus . . . . 10

2 Davis-Swisher Biological Treatment Reactors . $~ . \quad$. . . 12

3 Effluent Chemical Oxygen Demand Versus Time for

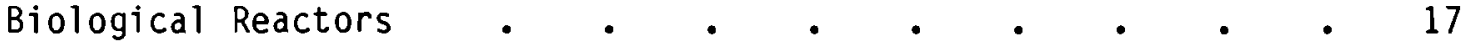

Chemical Oxygen Demand Removal Efficiency Versus Time
for Biological Reactors.

5 Solids and Hydraulic Retention Times Versus Time for

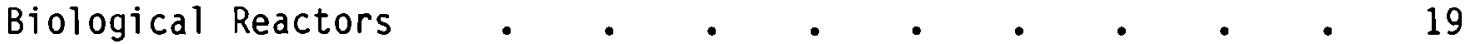

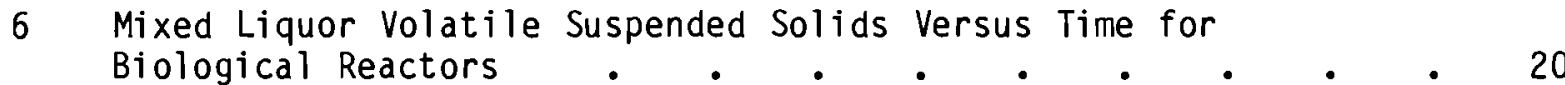

7 Effluent Chemical Oxygen Demand and $\mathrm{pH}$ Versus Time for

Blank Reactor. $. . . \quad . \quad . \quad . \quad . \quad . \quad 21$

8 Total Ion Chromatogram for Acid Fraction of Raw BGW . . . 24

9 Total Ion Chromatogram for Acid Fraction of WAO

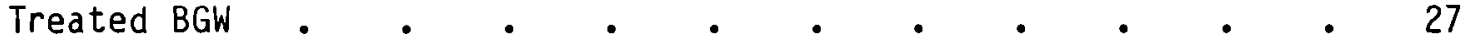

10 Total Ion Chromatogram for Acid Fraction of
Biological Effluent.

11 Total Ion Chromatogram for Neutral Fraction of Raw BGW. - . 32

12 Total Ion Chromatogram for Neutral Fraction of WAO

Total Ion Chromatogram for Neutral Fraction of
Biological Effluent. . . . . . . . . 37

14 Total Ion Chromatogram for Basic Fraction of Raw BGW . . . 40

Total Ion Chromatogram for Basic Fraction of WAO
Treated BGW

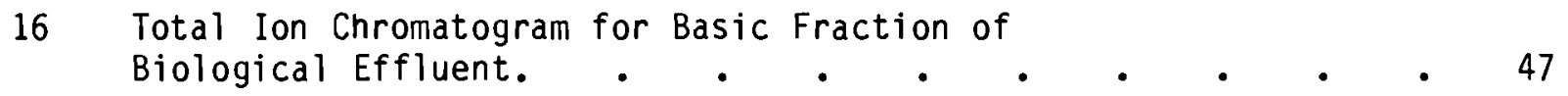




\section{TABLES}

1 Characteristics of Biomass Gasification Wastewater $\quad$ - $\quad$. 4

2 Results of BGW Treatment Studies at PNL Using Activated Sludge • 6

3 Summary of Wet Air 0xidation Treatment Conditions. $\quad$ - . . 11

4 Summary of Biological Reactor Operating Conditions . . - e 13

5 Mass Balance for the Wastewater Fractionation Procedure $\quad$ - 22

6 Components Identified in Acid Fraction of Raw BGW. $\quad$ - . $\quad 23$

7 Components Identified in Acid Fraction of WAO Treated BGW . • 26

8 Components Identified in Acid Fraction of Biological

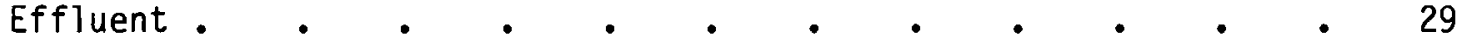

9 Components Identified in Neutral Fraction of Raw BGW . . . 31

10 Components Identified in Neutral Fraction of WAO

11 Components Identified in Neutral Fraction of

Biological Effluent. • • • • • • • • • • 36

12 Components Identified in Basic Fraction of Raw BGW . $\quad$ • $\quad 39$

Components Identified in Basic Fraction of WAO
Treated BGW

14 Components Identified in Basic Fraction of 


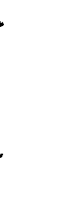


This report describes a lab-scale treatability study for using thermal and biological oxidation to treat a biomass gasification wastewater (BGW) having a chemical oxygen demand (COD) of $46,000 \mathrm{mg} / 1$. Wet air oxidation (WAO) at $300^{\circ} \mathrm{C}$ and $13.8 \mathrm{MPa}$ (2000 psi) was used to initially treat the BGW and resulted in a COD reduction of $74 \%$. This was followed by conventional activated sludge treatment using operating conditions typical of municipal sewage treatment plants. This resulted in an additional 95\% COD removal. Overall COD reduction for the combined process was $99 \%$.

A detailed chemical analysis of the raw BGW and thermal and biological effluents was performed using gas chromatography/mass spectrometry (GC/MS). These results showed a $97 \%$ decrease in total extractable organics with WAO and a 99.6\% decrease for combined WAO and activated sludge treatment. Components of the treated waters tended to be fewer in number and more highly oxidized.

An experiment was conducted to determine the amount of COD reduction caused by volatilization during biological treatment. Unfortunately, this did not yield conclusive results.

Treatment of BGW using WAO followed by activated sludge appears to be very effective and investigations at a larger scale are recommended. 


\section{CONCLUSIONS}

Treatment of BGW by WAO and activated sludge is highly effective for COD removal.

The thermal and biological oxidations greatly reduced the amount of organics in the water, but did not change the relative proportions of acid, neutral, and basic fractions.

The predominant reaction during WAO appeared to be oxidation of components in the acid fraction to form acids.

Both WAO and biological oxidation were more effective with the acidic and neutral fractions than with the basic fraction.

Activated sludge treatment of WAO treated BGW should be possible at higher organic loading rates than those used in this study.

Compared to previous studies with BGW, WAO appears to greatly increase the biological treatability of this wastewater. 


\section{RECOMMENDATIONS}

Based on the results of this study, the WAO/activated sludge process should be investigated further for treatment of BGW. Specific objectives should be:

- study various reaction temperatures and times for WAO to define optimum conditions;

- conduct activated sludge treatment at higher organic loading rates;

- determine the sludge settling characteristics of the activated sludge ;

- determine the kinetic coefficients for biological treatment so that the process can be optimized;

- demonstrate the technology at a larger scale.

In addition, lab scale treatment of BGW using WAO followed by anaerobic biological treatment should be investigated. 


\section{INTRODUCTION}

Thermochemical conversion of biomass (animal manure, woodchips, straw, etc.) is being developed as a source of synthetic natural gas. In the process of gasification, water and some organic chemicals condense to form a wastewater having an organic strength 100 times that of than domestic sewage. Several laboratory scale methods for treating these high strength wastewaters have been previously investigated at the U.S. Department of Energy's Pacific Northwest Laboratory (PNL) by Wakamiya, Maxham and Petty (1979); Maxham and Bell (1980); Maxham and Wakamiya (1980); Wakamiya and Maxham (1980); Bell (1981); English (1981); and Petty, Eliason and Laegreid (1981). These methods included aerobic and anaerobic biological treatment, activated carbon adsorption, coagulation/ flocculation, reverse osmosis, solvent extraction, and wet air oxidation (WAO). The highest chemical oxygen demand (COD) removals were obtained with aerobic biological and WAO treatment. Results of these studies showed, however, that no one treatment method was suitable for treating this high strength wastewater to a level acceptable for discharge.

This study was undertaken to investigate a two-step treatment process consisting of wet air oxidation followed by aerobic biological treatment. Results of previous studies suggested that this combination should be capable of achieving a high level of treatment with biomass gasification wastewaters (BGW). Wastewater for this study was obtained from the Synthes is Gas From Manure (SGFM) gasifier at Texas Tech University in Lubbock, Texas. Characteristics of this wastewater are given in Table 1.

$\begin{array}{lr}\text { TABLE 1. Characteristics of Biomass Gasification Wastewater } \\ \text { Chemical 0xygen Demand (COD) } & 46,000 \mathrm{mg} / 1 \\ \text { Total Suspended Solids } & 1,100 \mathrm{mg} / 1 \\ \text { Volatile Suspended Solids } & 940 \mathrm{mg} / 1 \\ \text { pH } & 3.7\end{array}$


Specific objectives of this study were:

- to determine the feasibility of the WAO/activated sludge process for treating BGW at a small scale using typical operating conditions;

- to determine the chemical composition of raw BGW and WAO and activated sludge effluents; and

- to gain understanding of the processes and transformations that occur during the different treatment steps. 
BACKGROUND

Several investigations of aerobic biological treatment of BGW have been made at PNL. Results of studies using the activated sludge process are summarized in Table 2. The high rate fixed film (HRFF) process is similar to conventional activated sludge except that inert, nigh density solids are placed in the aeration zone for microorganisms to attach to. This allows a much higher concentration of biomass in the aeration zone, and consequently, higher organic loading rates.

Wet air oxidation was also investigated at PNL as a means of treating full strength BGW (English 1981). The results of this study were encouraging with a maximum of $80 \%$ COD reduction occurring with treatment at $300^{\circ} \mathrm{C}$ and $13.8 \mathrm{MPa}$ (2000 psi). This removal was obtained after 20 min of treatment and additional treatment, up to a maximum of $180 \mathrm{~min}$, did not result in significantly greater removal.

TABLE 2. Results of BGW Treatment Studies at PNL Using Activated Sludge

\begin{tabular}{|c|c|c|c|c|}
\hline Investigators & $\begin{array}{l}\text { Treatment } \\
\text { Type }\end{array}$ & Feed & $\begin{array}{l}\text { Organic Loading } \\
\text { Rate mg cOD/1-day } \\
\text { (1b COD/1000 } \mathrm{ft}^{3} \text {-day) }\end{array}$ & $\begin{array}{l}\text { COD } \\
\text { Removal, \% } \\
\end{array}$ \\
\hline $\begin{array}{l}\text { Wakamiya, Maxham } \\
\text { and Petty (1979) }\end{array}$ & $\begin{array}{l}\text { Conventional } \\
\text { AS }\end{array}$ & $\begin{array}{l}1 \% \text { BGW } \\
\text { in water }\end{array}$ & $960(60)$ & 75 \\
\hline \multirow[t]{4}{*}{$\begin{array}{l}\text { Wakamiya and } \\
\text { Maxham (1980) }\end{array}$} & HRFF & $\begin{array}{l}10 \% \mathrm{BGW} \\
\text { in water }\end{array}$ & $880(55)$ & 65 \\
\hline & & $\begin{array}{l}10 \% \mathrm{BGW} \\
\text { in water }\end{array}$ & $980(61)$ & 82 \\
\hline & & $\begin{array}{l}10 \% \text { BGW } \\
\text { in water }\end{array}$ & $1700(110)$ & 80 \\
\hline & & $\begin{array}{l}10 \% \text { BGW } \\
\text { in water }\end{array}$ & $3400(220)$ & 75 \\
\hline $\begin{array}{l}\text { Maxham and } \\
\text { Wakamiya (1980) }\end{array}$ & HRFF & $100 \%$ BGW & $2400(150)$ & 77 \\
\hline $\begin{array}{l}\text { Maxham and } \\
\text { Bell (1980) }\end{array}$ & HRFF & $100 \%$ BGW & $3500(220)$ & 70 \\
\hline
\end{tabular}


Only limited data were available on the chemical composition of BGW. Kao (1980) reported that most COD was due to low molecular weight organics such as formic, acetic, and propionic acids, methanol, ethanol and acetone. The remainder was thought to consist mainly of larger volatile aromatic and aliphatic compounds.

The above chemical composition would help explain the limitations noted in both biological and WAO treatment. The low molecular weight acids and alcohols are readily degraded biologically, so that they would be removed easily at the high organic loading rates used with the HRFF process. The larger organics are more resistant to biologial degradation and would not be removed as readily at the high loading rates necessary for economical treatment of high strength wastes. Further COD reduction would probably require lower loading rates and longer retention times, resulting in much higher treatment costs.

Chemical composition has quite a different effect on WAO. Large organic compounds are readily broken down by WAO while low molecular weight compounds, particularly acids, are very resistant to further oxidation. This explains the rapid initial COD reduction seen with WAO and also explains why a maximum removal is reached. Based on results with $B G W$, additional COD removal beyond $80 \%$ would probably have required excessively high temperatures and pressures, leading to uneconomical treatment.

Based on the above considerations, a two-step treatment process consisting of WAO followed by activated sludge seemed very promising. The WAO should result in a rapid initial reduction of COD and destruction of large, poorly biodegradable organics. The WAO effluent should consist of primarily low molecular weight organics, which are readily removed by biological treatment.

The above treatment process also has advantages with respect to energy consumption. Most of the energy required for WAO is for heating the wastewater to treatment temperature. Since heat is generated during the oxidation of organic matter, energy use becomes less as waste strength increases. This would favor the use of WAO as the first treatment step. The opposite is true with activated sludge treatment. Most of the energy use is for aerating wastewater. For a given COD removal efficiency, energy use increases as waste strength increases. Activated sludge treatment would, therefore, be most efficient as the second treatment step. 
Because of the apparent advantages to the wet air oxidation/activated sludge (WAO/AS) treatment process, it was decided to conduct a bench scale treatability study. The objective of this was to determine the effectiveness of the process under typical large scale operating conditions. In addition, since the effectiveness of the treatment method depends strongly on the composition of the wastewater, detailed chemical characterizations of the raw BGW and WAO and biologically treated effluents was planned. This would hopefully allow better understanding of the chemical transformations occuring during treatment. This would be helpful in designing future optimization studies if the method looked promising. 
EXPERIMENTAL PROCEDURE

Experimental procedures are discussed in four major groups, corresponding to the major parts of the study. These are wet air oxidation of raw BGW, activated sludge treatment of wet oxidized BGW, determination of volatile COD losses during biological treatment, and chemical analysis of raw and treated BGW.

WET AIR OXIDATION OF BGW

Wet air oxidation was performed in a 3.78 ( 1 gal) Hastelloy $C$ autoclave, as described previously by English (1981). A sketch of this equipment is given in Figure 1. Raw BGW was filtered through a Number 1 whatman filter to remove char and refrigerated at $4^{\circ} \mathrm{C}$ until treatment. The treatment procedure consisted of loading the autoclave with sample, charging with air to the operating pressure, heating the autoclave and contents to operating temperature, stirring the autoclave contents vigorously for the desired reaction time, quenching the reaction, cooling and depressurizing the autoclave, and unloading the treated sample. Operating conditions are summarized in Table 3 . These conditions were selected based on the results of English (1981) and on consideration of possible conditions that might be applied in larger scale treatment.

\section{BIOLOGICAL TREATMENT}

Biological treatment was done using the Davis-Swisher apparatus described previously by Maxham and Wakamiya (1980). A sketch of this apparatus is shown in figure 2. These reactors have a volume of $290 \mathrm{ml}$ in the aeration zone and $50 \mathrm{ml}$ in the settling zone. Daily activities associated with reactor maintenance included measuring effluent volumes, preserving effluent samples for COD analysis, obtaining feed samples for COD analysis, measuring reactor $\mathrm{pH}$, wasting activated sludge (when needed), preserving waste sludge samples for solids determination, and cleaning inside reactor walls by washing with clarified effluent. Sludge was wasted by pipetting from the aerated zone of the reactor and replacing the waste volume with distilled water. Reactor feed was prepared by filtering wet oxidized BGW through $0.45 \mu$ filters, adding 


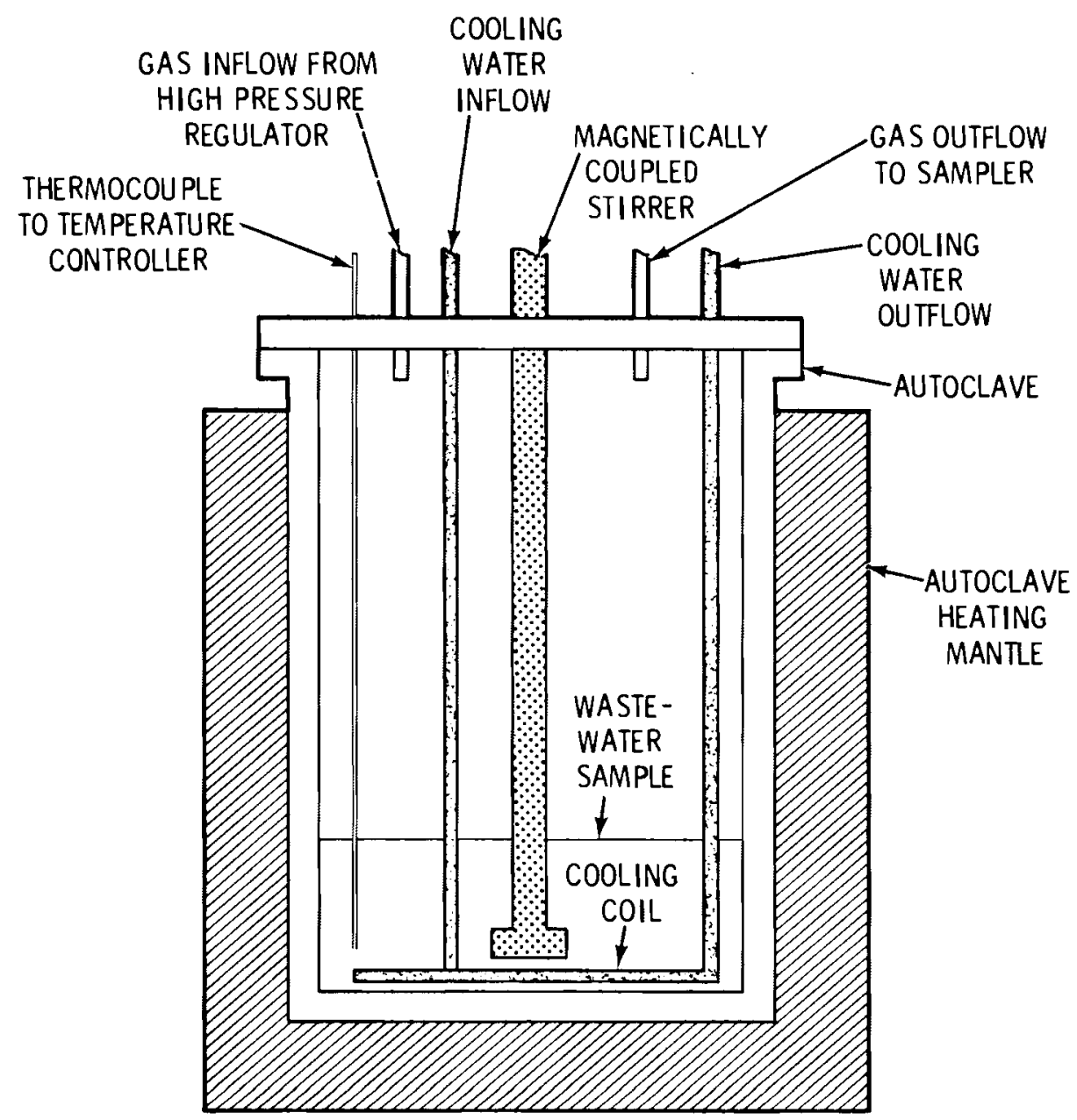

FIGURE 1. Laboratory Scale Wet Air Oxidation Apparatus 
TABLE 3. Summary of Wet Air Oxidation Treatment Conditions

$\begin{array}{ll}\text { Temperature } & 300^{\circ} \mathrm{C}\left(572^{\circ} \mathrm{F}\right) \\ \text { Pressure } & 13.8 \mathrm{MPa}(2000 \mathrm{psi}) \\ \text { Reaction Time } & 20 \mathrm{~min} \\ \text { Stirrer Speed } & 1000 \mathrm{rpm} \\ \text { Sample Volume } & 1130 \mathrm{ml}\end{array}$

$2 \mathrm{~g} / 1$ ammonium phosphate for nutrients and adjusting the $\mathrm{pH}$ to 5.0 with $10 \mathrm{~N}$ $\mathrm{NaOH}$. Reactors were fed using Masterflex pumps with 7013 pumpheads. An electronic timer controlled the pumps and provided feed every three hours. Air going to the reactors was first saturated by bubbling through a humidifier to prevent evaporative loss of reactor contents.

A summary of reactor feed and operating conditions is provided in Table 4. Reactors were initially started using $300 \mathrm{ml}$ of activated sludge from the Union $0 i l$ Refinery near Rodeo, California. Reactors were then acclimated to an artificial feed consisting of $5 \mathrm{~g} / 1$ acetate (from sodium acetate) and $2 \mathrm{~g} / 1$ of dried milk solids. Acetate was selected as a major constituent of the artificial feed since acetic acid was expected to be the major component of the wet oxidized BGW. The reactors were operated on the artificial feed for two months. This was longer than initially intended because of delays in obtaining samples of raw BGW.

Once wet oxidized BGW was obtained, reactors were gradually adapted to this feed. Initially, they were fed a mixture of $25 \%$ wet oxidized effluent and $75 \%$ artificial feed. This was gradually increased over three weeks to $100 \%$ wet oxidized BGW.

After six weeks of operation with full strength wet oxidized feed the autoclave developed difficulties. The supply of wet oxidized feed was interrupted and the reactors were fed effluent from earlier biological treatment of artificial feed for one week. Because of a faulty autoclave seal and heating mantle, the next treatment was 1 imited to $209^{\circ} \mathrm{C}$. This water was stronger than the $300^{\circ} \mathrm{C}$ water and appeared much darker in color so it was diluted $25 \%$ with WAO/AS effluent. The reactors were fed this mixture for two and one-half weeks. 


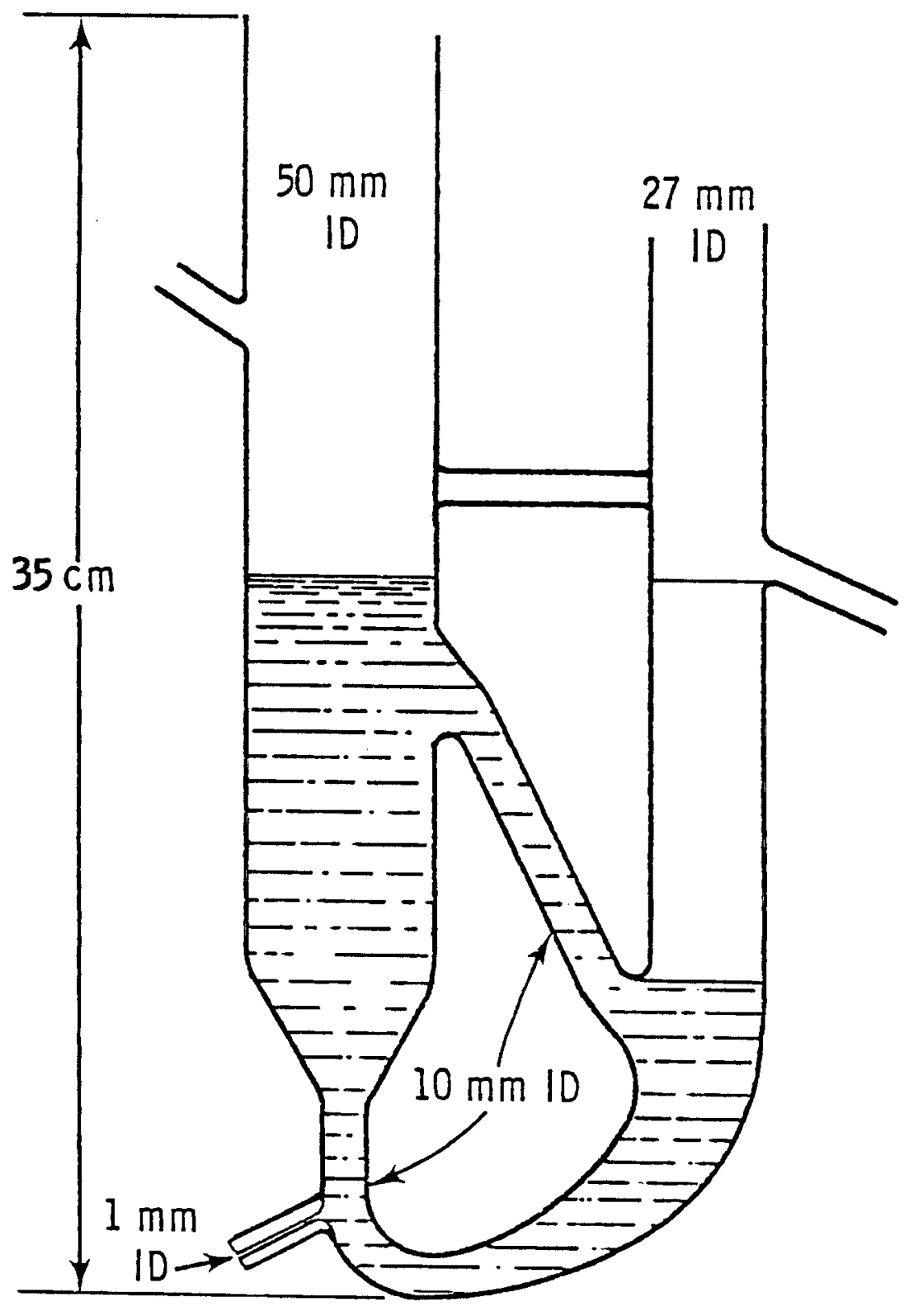

FIGURE 2. Davis-Swisher Biological Treatment Reactors 
TABLE 4. Summary of Biological Reactor Operating Conditions

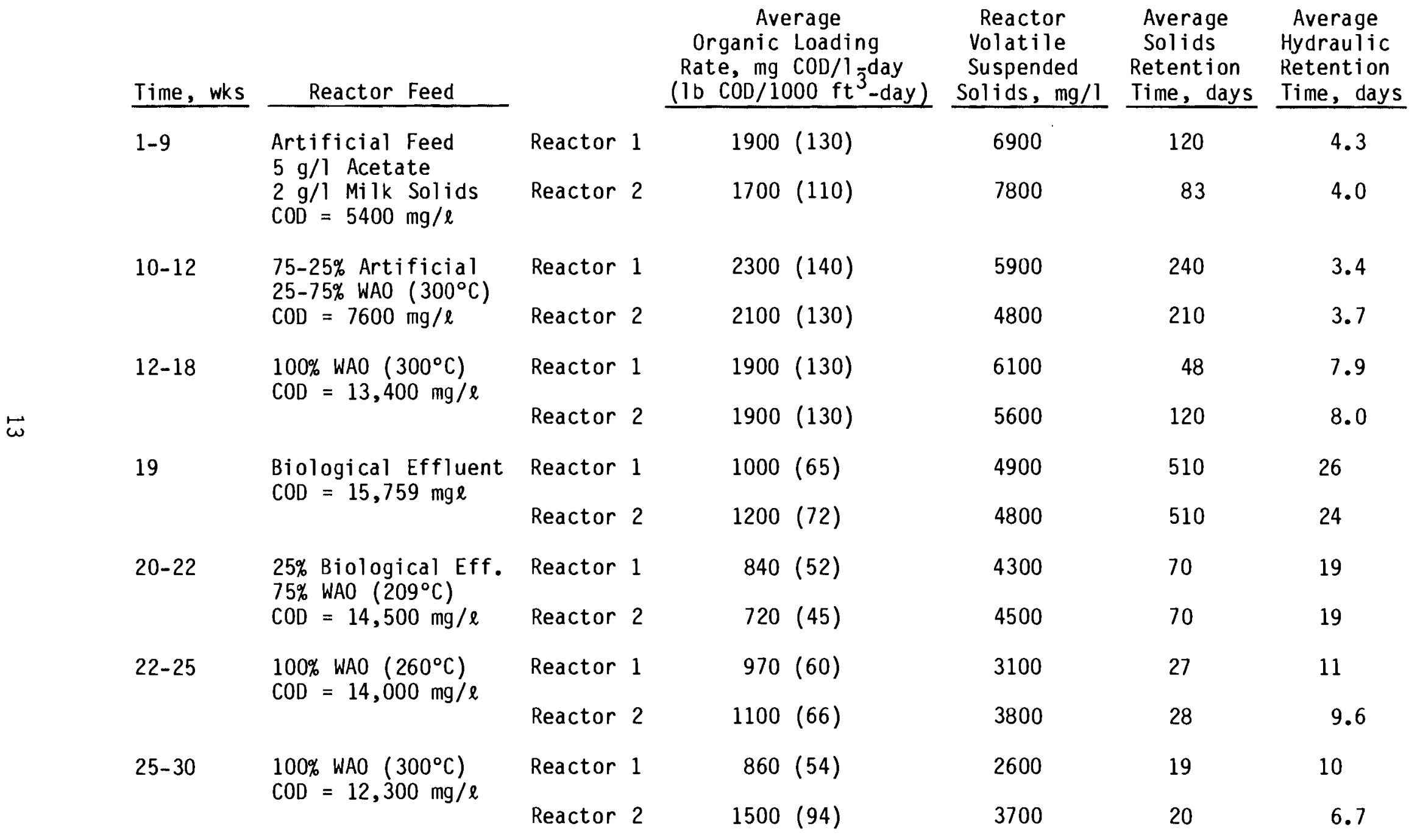


The next treatment reached a temperature of $260^{\circ} \mathrm{C}$. Since this water was approximately the same strength as the $300^{\circ} \mathrm{C}$ water, it was fed full strength. After three and one-half weeks with this feed, the autoclave was completely repaired and feeding with full strength $300^{\circ} \mathrm{C}$ water resumed. This continued for the remaining six weeks of reactor operation.

DETERMINATION OF VOLATILE COD LOSSES

Since the wet air oxidized BGW was expected to contain a high concentration of volatile acids, it was felt that volatilization during aeration might be a mechanism for COD reduction during biological treatment. A blank DavisSwisher reactor was set up in an attempt to determine the extent of such volatile losses. Initially, this unit was filled with WAO/AS effluent which had been filtered through a $0.45 \mu$ filter. The blank received the same feed and aeration rate as the biological reactors. After one week of operation, significant biological growth was noted and the unit was stopped. Contents were again filtered and mercuric chloride added at a rate of $0.2 \mathrm{mg} / 1$ to suppress biological growth. Feed was added to replace the contents lost during filtration. The blank unit was then restarted and run for two weeks.

\section{CHEMICAL ANALYSES}

Chemical oxygen demand and volatile suspended solids were determined using the procedures given in Standard Methods (APHA 1980).

The composition of the raw BGW and treated effluents was determined by gas chromatography (GC) and gas chromatography/mass spectrometry (GC/MS). Prior to analysis the raw wastewater and wet oxidation treated waters were filtered through a 4 to $8 \mu$ glass fritted filter. The biological effluent water had previously been filtered through a $50 \mu$ Whatman filter. Organics were extracted from the wastewaters using an acid-base procedure. Each type of wastewater was extracted in duplicate or triplicate. In each case $100 \mathrm{ml}$ of water was acidified to $\mathrm{pH} 1$ with $6 \mathrm{M} \mathrm{H}_{2} \mathrm{SO}_{4}$ and extracted three times with methylene chloride (DCM). The water was adjusted to $\mathrm{pH} 12$ with $6 \mathrm{M} \mathrm{NaOH}$ and extracted three times with DCM to give the basic fraction. The first DCM 
fraction was extracted three times with $5 \% \mathrm{NaOH}$ to yield the neutral fraction in DCM and acids in the aqueous portion. The acids were extracted into DCM after adjusting the aqueous phase to $\mathrm{pH} 1$ with $6 \mathrm{M} \mathrm{H}_{2} \mathrm{SO}_{4}$.

All fractions were analyzed by fused silica capillary gas chromatography on two different columns: a moderately polar SE-52 and a polar Carbowax column. Duplicate (or in some cases, triplicate) samples showed similar chromatograms and were combined for GC/MS analysis. The wet oxidation samples were very similar and were also combined for GC/MS analysis. Chromatograms of procedural blanks showed only a very few weak peaks and did not appear to contribute to the peaks of interest. For GC/MS analysis, either an SE-54 (similar to SE-52) or Carbowax column was used, depending on the GC results. The basic fractions chromatographed better on SE-54, whereas the acid and neutral fractions gave better results on the Carbowax column. The temperature program for SE-54 started at $20^{\circ} \mathrm{C}$, then programmed at $5^{\circ} /$ min to $320^{\circ} \mathrm{C}$ and held isothermal for $10 \mathrm{~min}$. For the Carbowax column the initial temperature was $20^{\circ} \mathrm{C}$ and the column was programmed at $10^{\circ} / \mathrm{min}$ to $220^{\circ} \mathrm{C}$, where it was held isothermal for $10 \mathrm{~min}$. The mass spectrometer was used in EI mode at $70 \mathrm{eV}$. Both computerized and manual literature searches were accomplished with the EPA-NIH data base. 


\section{RESULTS}

WET AIR OXIDATION

Wet air oxidation of the raw $\mathrm{BGW}$ at $300^{\circ} \mathrm{C}$ for 20 min resulted in an average COD reduction of $74 \%$. Results from run to run were very consistent, ranging only from 73 to $75 \%$. One run made at $260^{\circ} \mathrm{C}$ for 20 min resulted in $68 \%$ COD removal. One run made at $209^{\circ} \mathrm{C}$ for 20 min resulted in $\sim 60 \%$ COD removal.

BIOLOGICAL TREATMENT

Biological treatment of the wet oxidized BGW resulted in an average COD reduction of $95 \%$ over the period the reactors were fed full strength wet oxidized BGW. Combined with the COD removal during wet oxidation, the overall COD removal efficiency was 99\%. Effluent CODs for the biological treatment units are shown in Figure 3. Week 12 corresponds to the start of full strength wet oxidized feed. The COD removal efficiency, solids retention time (SRT), hydraulic retention time (HRT), and mixed liquor volatile suspended solids (MLVSS) for the two reactors over the same period of time are shown in Figures 4 through 6 , respectively. It should be noted that figure 5 shows the average weekly SRT calculated as the quotient of the average MLVSS concentration and the average wasting rate. The large SRTs observed in some weeks reflect low wasting rates and have little meaning over short periods.

\section{VOLATILE COD LOSSES}

Results of the experiment to determine the volatile COD losses resulting from aeration are shown in 'Figure 7. These results include the actual effluent COD from the reactor, the expected COD if no volatile losses were occurring, and reactor $\mathrm{pH}$. These results are shown for the three week period of the experiment.

\section{CHEMICAL ANALYSES}

The amounts of the acid, base, and neutral fractions for each water, expressed as a percentage of the extracted organics, are shown in Table 5 . 


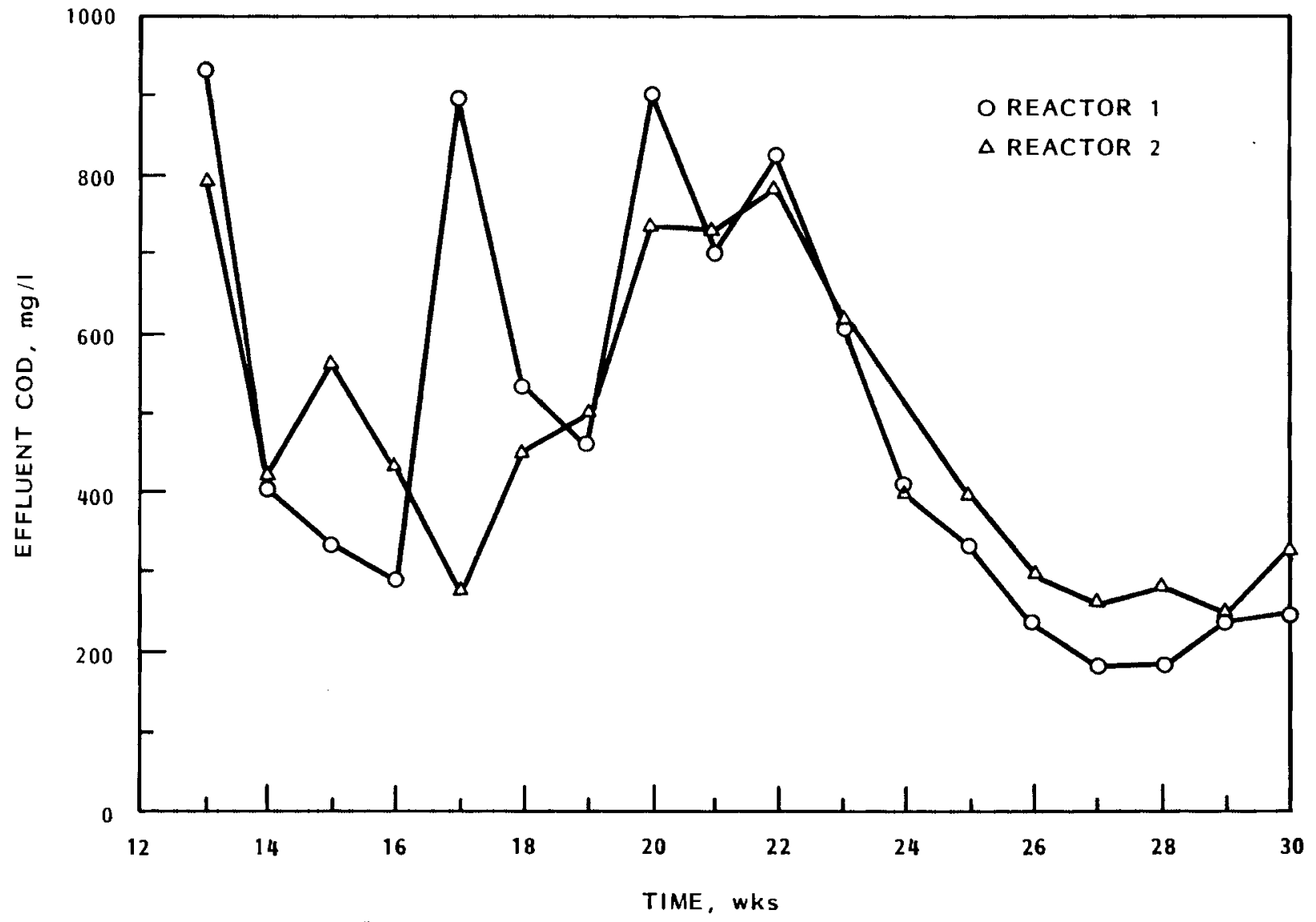

FIGURE 3. Effluent Chemical 0xygen Demand Versus Time for Biological Reactors 


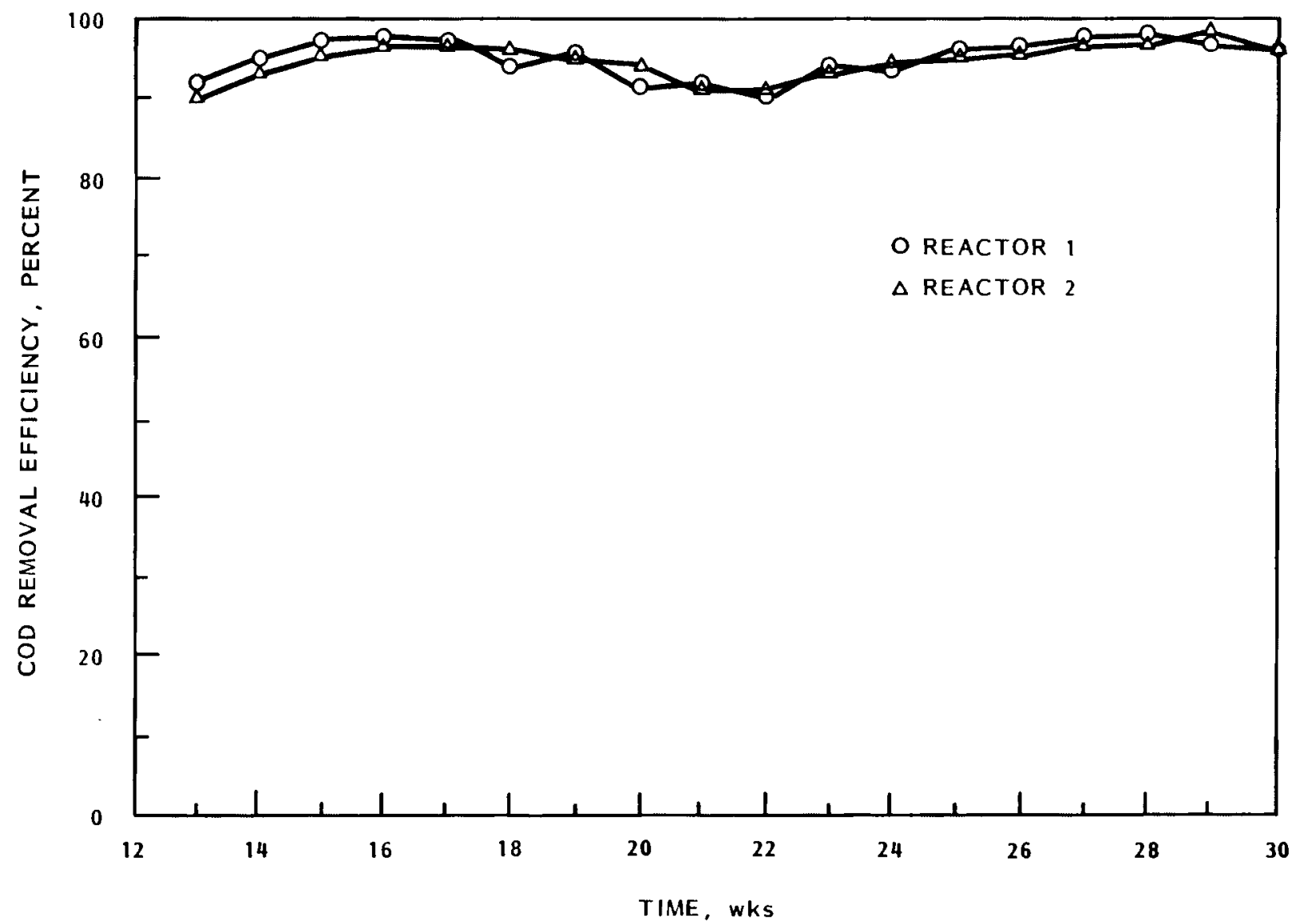

FIGURE 4. Chemical 0xygen Demand Removal Efficiency Versus Time for Biological Reactors 


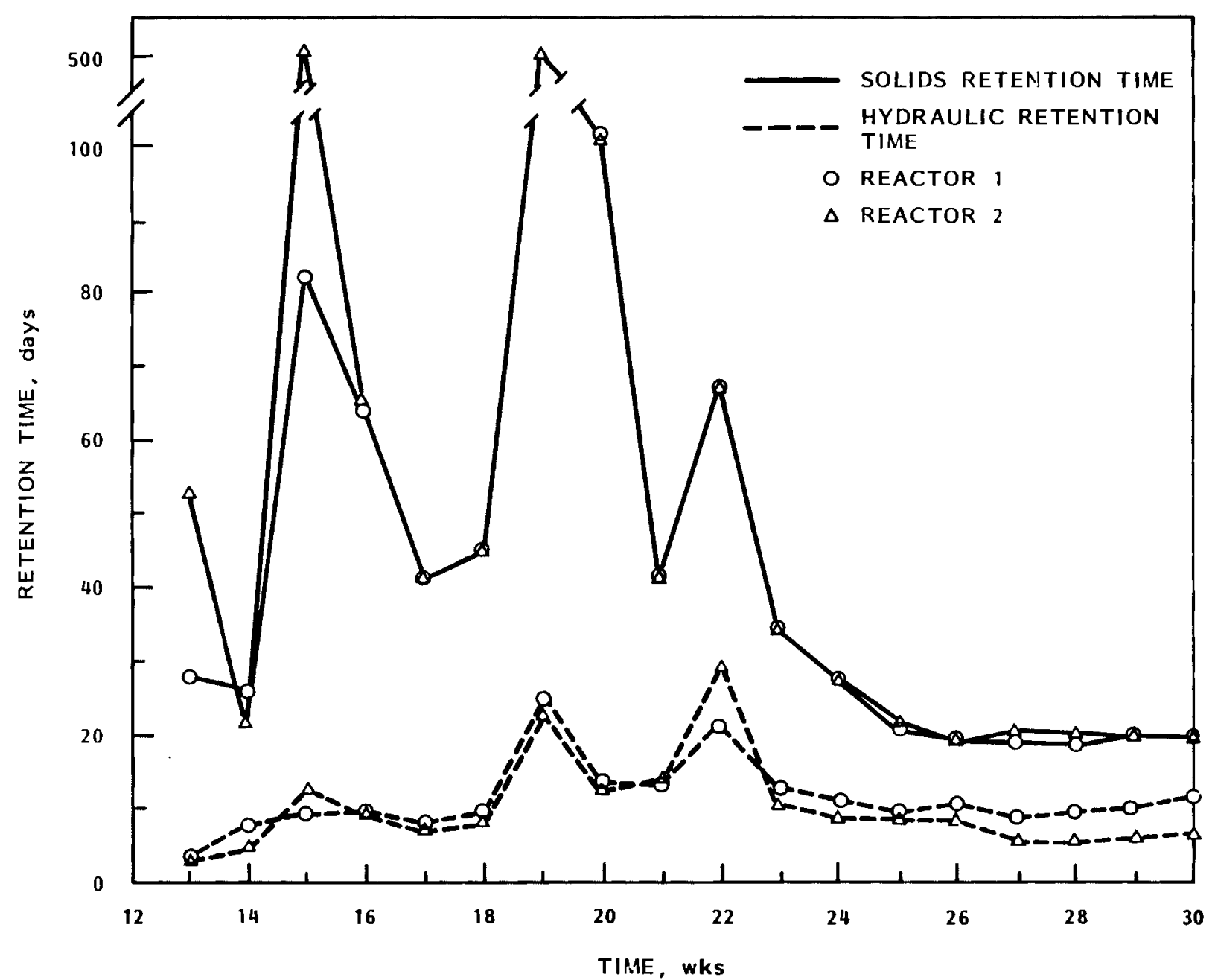

FIGURE 5. Solids and Hydraulic Retention Times Versus Time for Biological Reactors 


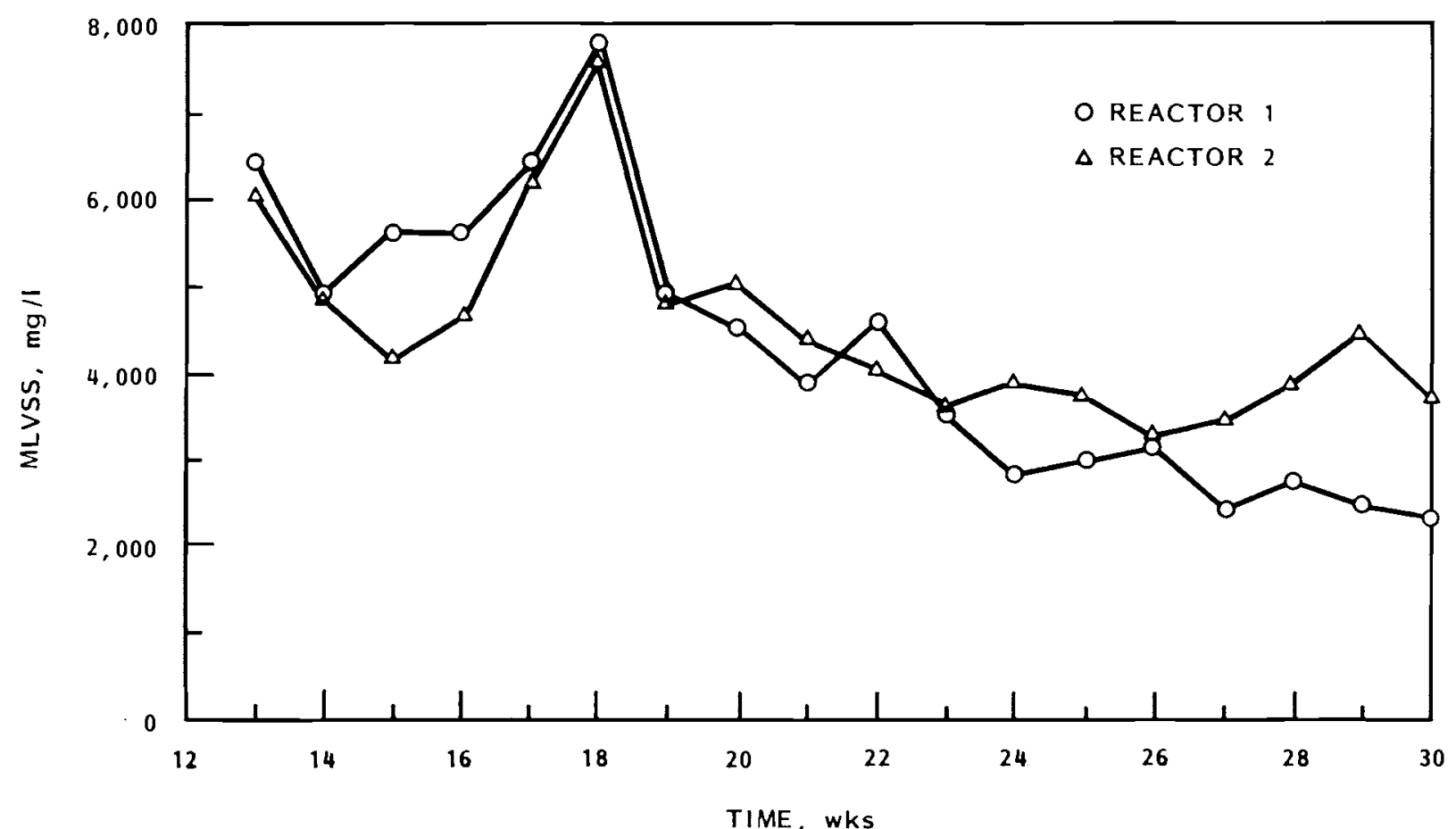

FIGURE 6. Mixed Liquor Volatile Suspended Solids Versus Time for Biological Reactors 


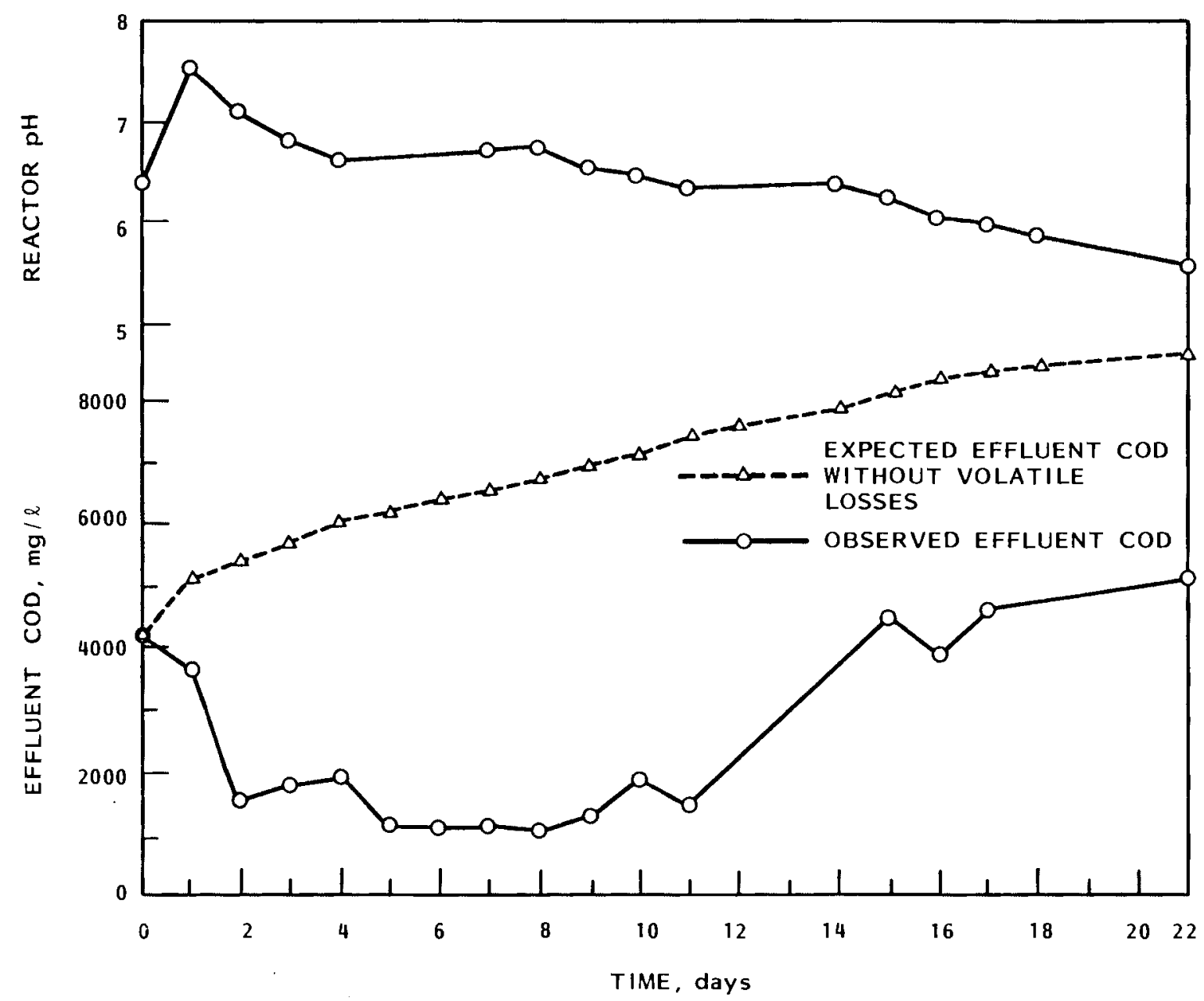

FIGURE 7. Effluent Chemical 0xygen Demand and pH Versus Time for Blank Reactor 
TABLE 5. Mass Balance for the Wastewater Fractionation Procedure \begin{tabular}{lccc}
$\begin{array}{c}\text { Total Weight } \\
\text { Extracted }(g)(a)\end{array}$ & $\begin{array}{c}\text { Acid } \\
\text { Fraction (\%) }\end{array}$ & $\begin{array}{c}\text { Basic } \\
\text { Fraction (\%) }\end{array}$ & Fraction (\%) \\
\hline
\end{tabular}

Raw 0.25 74

24 2

Wet Oxidation

0.007

70

26

$4-6^{(b)}$

Biological

Effluent

0.001

62

29

$g(b)$

(a) Sum of the weights of the three fractions extracted from $100 \mathrm{ml}$.

(b) These numbers were nigher $(\sim 20 \%)$ and the acid fractions correspondingly lower in one set of experiments. The discrepancy may have been due to emulsion problems.

Compounds identified in the various fractions of the waters are shown in Tables 6 through 14, along with the correspondingly labeled total ion chromatograms (Figures 8 through 16). GC retention data were available for a number of the compounds, notably most of the phenols and methoxy phenols in the acid fractions. All other identifications are based on mass spectral fragmentation patterns and must be considered tentative. The agreement between the sample and data base spectra is indicated in the tables. Distinction among isomers was not possible. 
TABLE 6. Components Identified in Acid Fraction of Raw BGW(a)

1. dihydrofuranone

2. methylbutenal

3. $C_{8}-$ cyclic ketone $^{(b)}$

4. methyl butenoic acid

5. hydroxy methyl cyclopentenone

6. guaiacol

7. $\mathrm{C}_{8}$-cyclic ketone

8. dimethylphenol

9. Co-singly unsaturated cyclic ketone.

10. phenol

11. methylphenols

12. ethylmethoxyphenol

13. ethylphenols

14. $C_{2}$-phenol

15. Unknown, $M^{+}=166$

16. trimethylphenol

17. ethylmethylphenol

18. C $C_{3}$-phenol

19. dimethylphenol

20. dimethoxyphenol

21. propenylphenol

22. dimethoxymethylphenol

23. ethylenyloxybenzene

24. dimethoxyethylphenol

25. ethylbenzal dehydes

26. $C_{3}$-singly unsaturated phenol

27. dimethoxypropenylphenol

28. hydroxymethoxybenzaldehyde (vanillin)

29. methylbenzofuran(c)

30. hydroxymethoxyphenylethanone (acetovanillin)

31. hydroxyphenylethanone

32. methoxybenzal dehyde

33. hydroxydimethoxybenzal dehyde

(a) Numbers correspond to those in Figure 8.

(b) Very uncertain.

(c) Uncertain, but reasonably good mass spectral fit. 


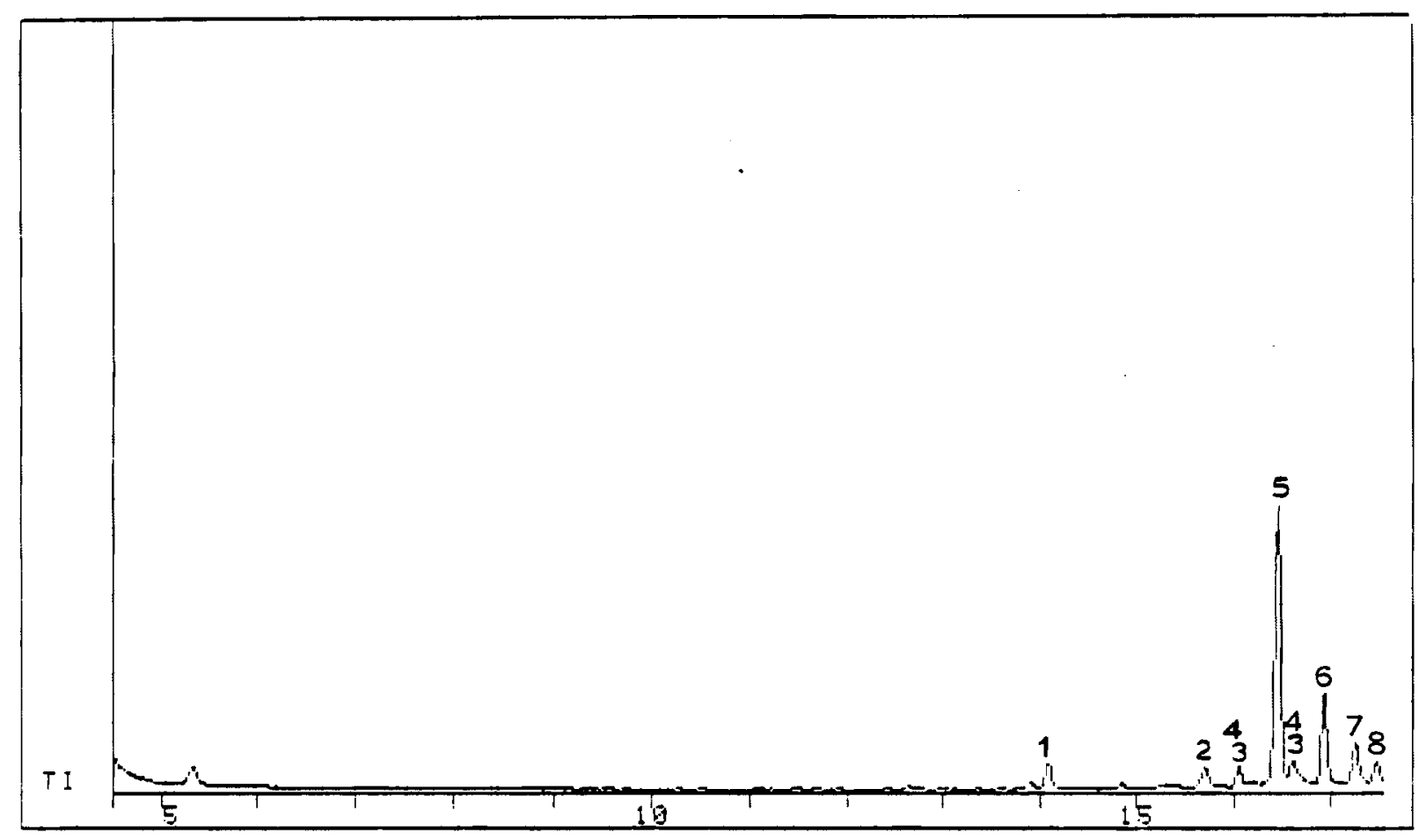

Retention Time, min

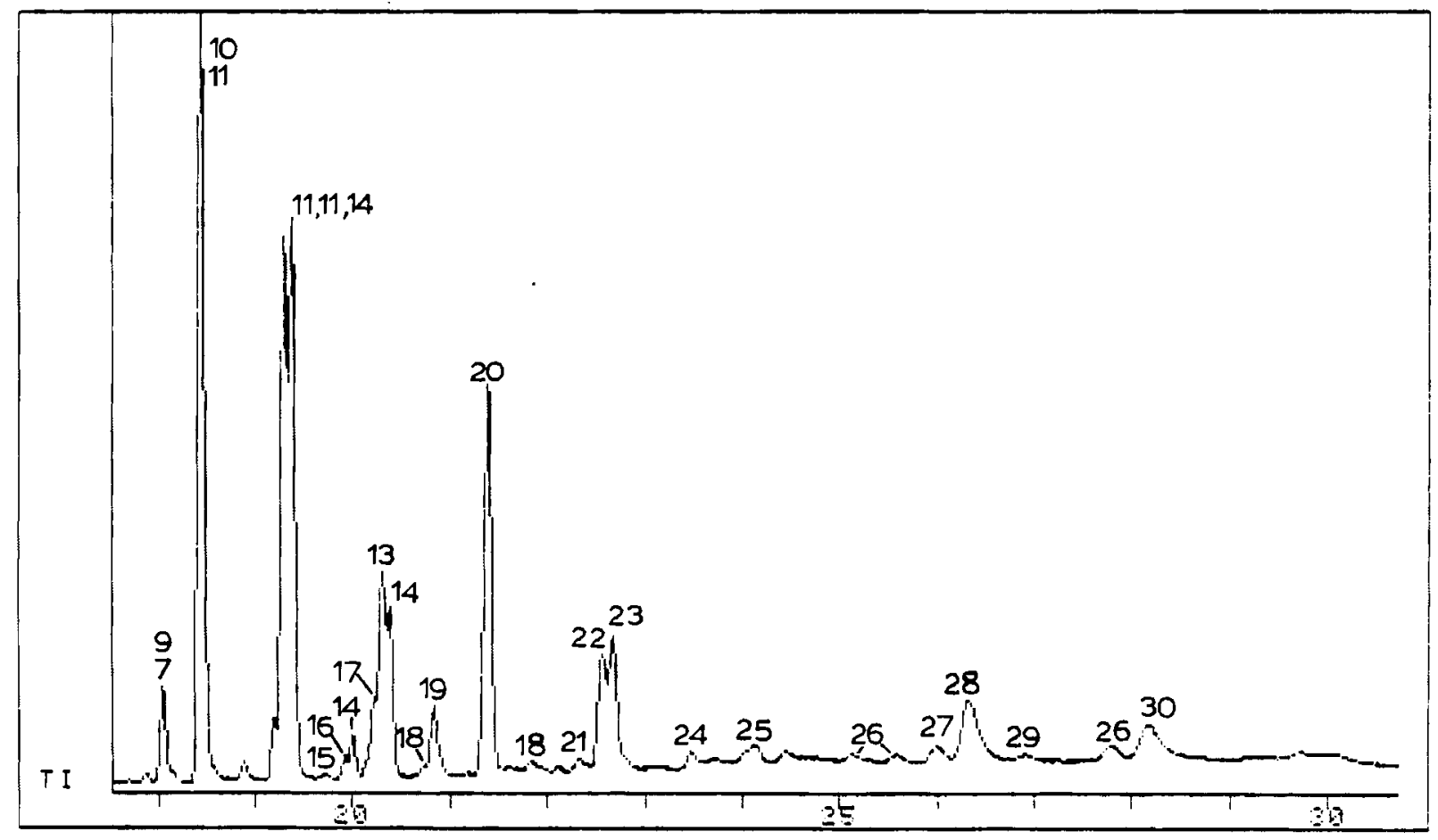

Retention Time, min

FIGURE 8. Total Ion Chromatogram for Acid Fraction of Raw BGW 


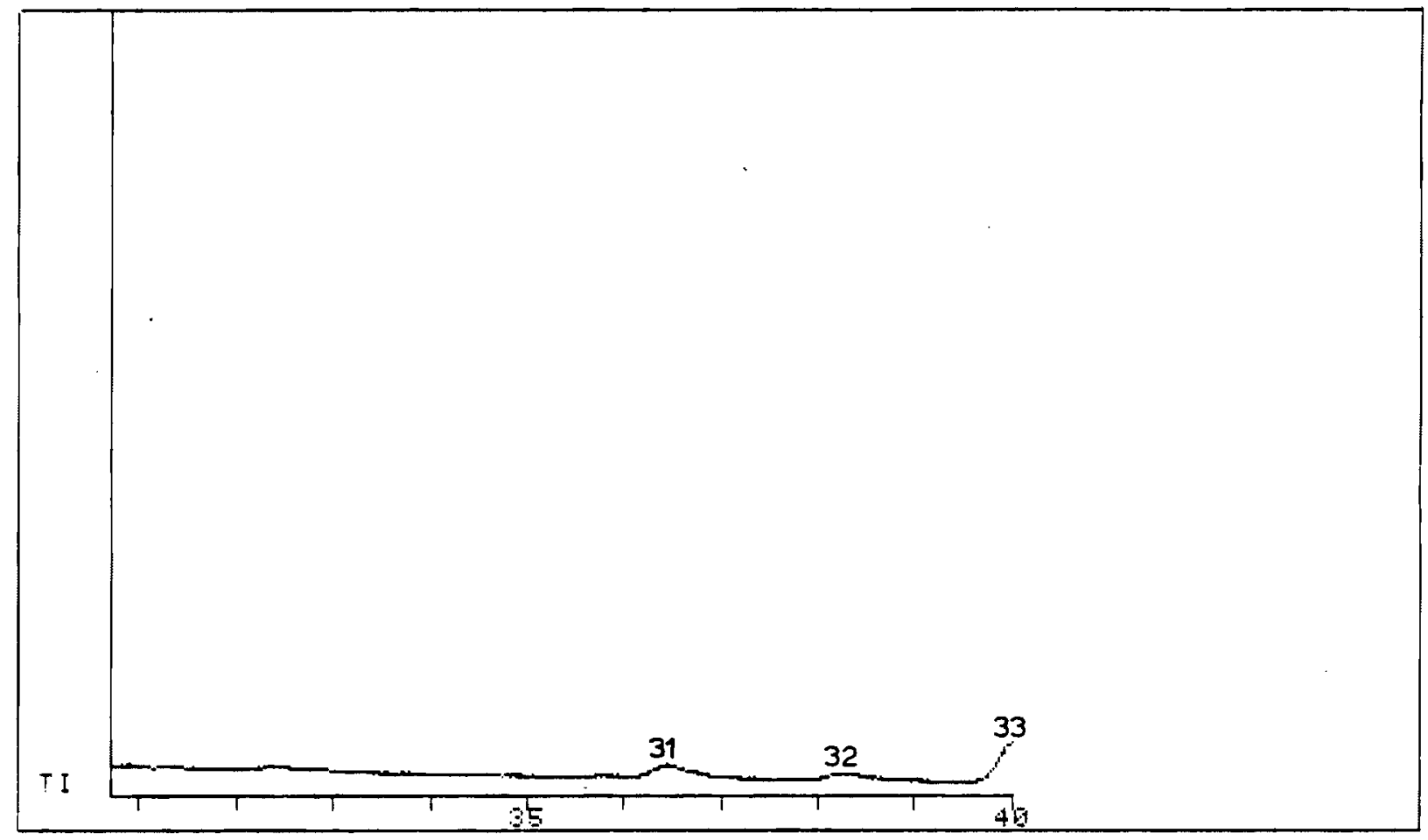

Retention Time, min

FIGURE 8. (contd) 
TABLE 7. Components Identified in Acid Fraction of WAO Treated BGW(a)

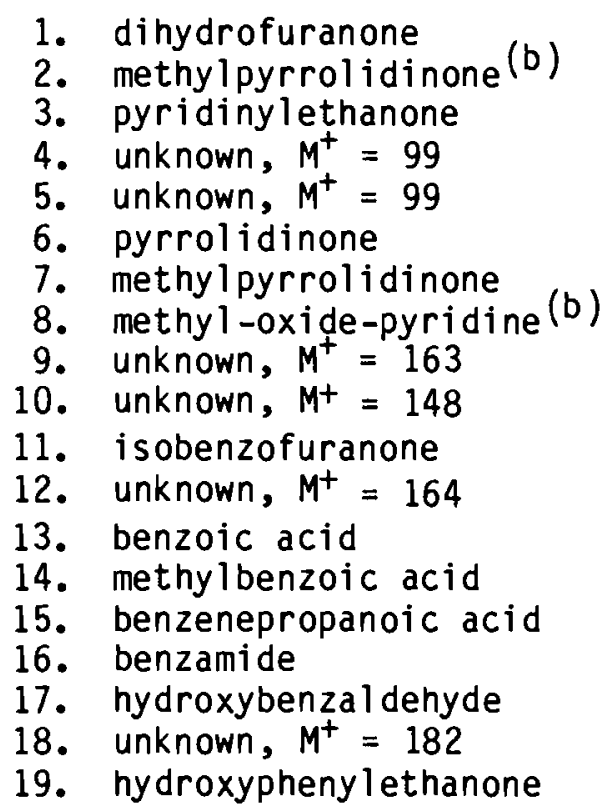

(a) Numbers correspond to those in Figure 9.

(b) Uncertain, but reasonably good mass spectral fit. 


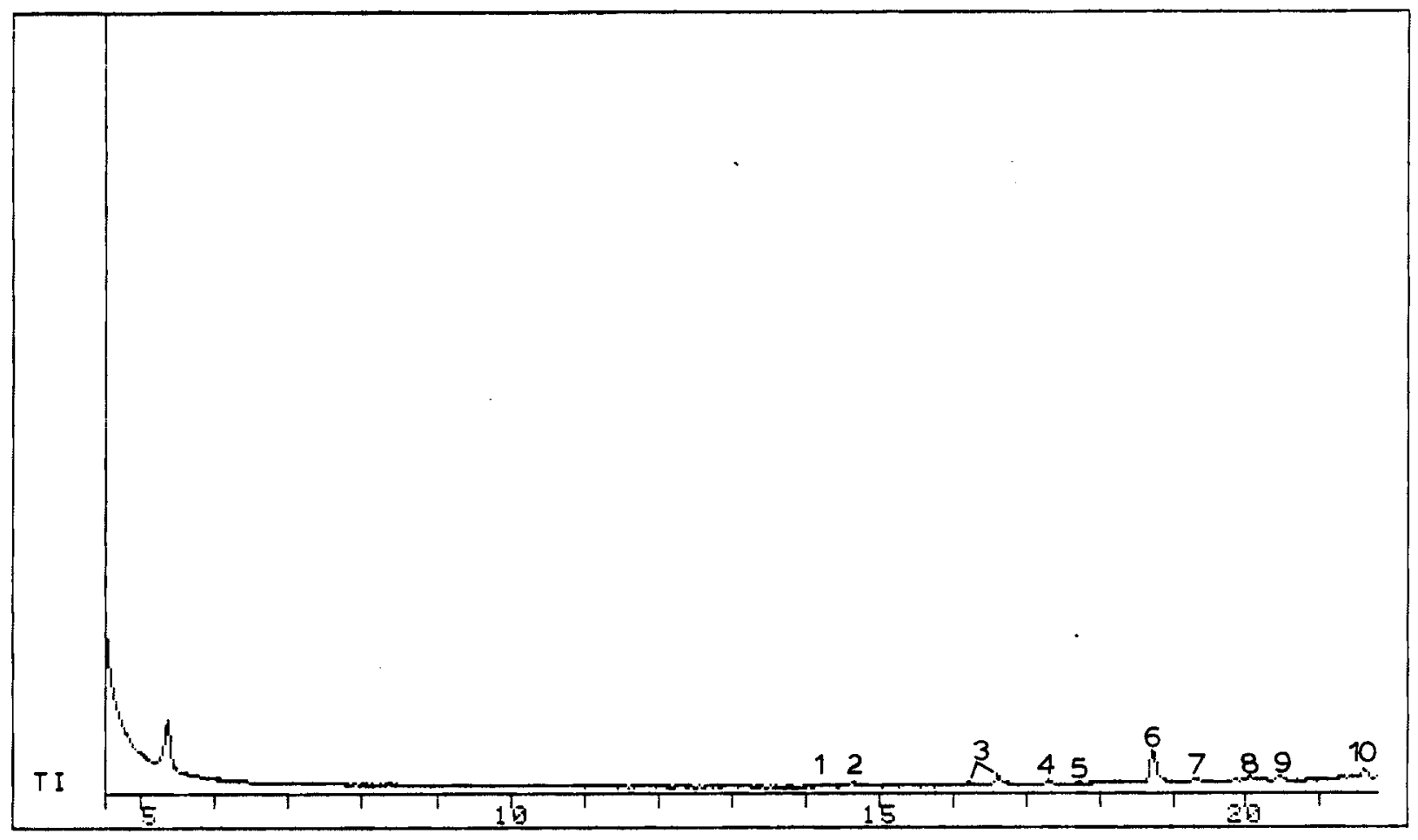

Retention Time, min

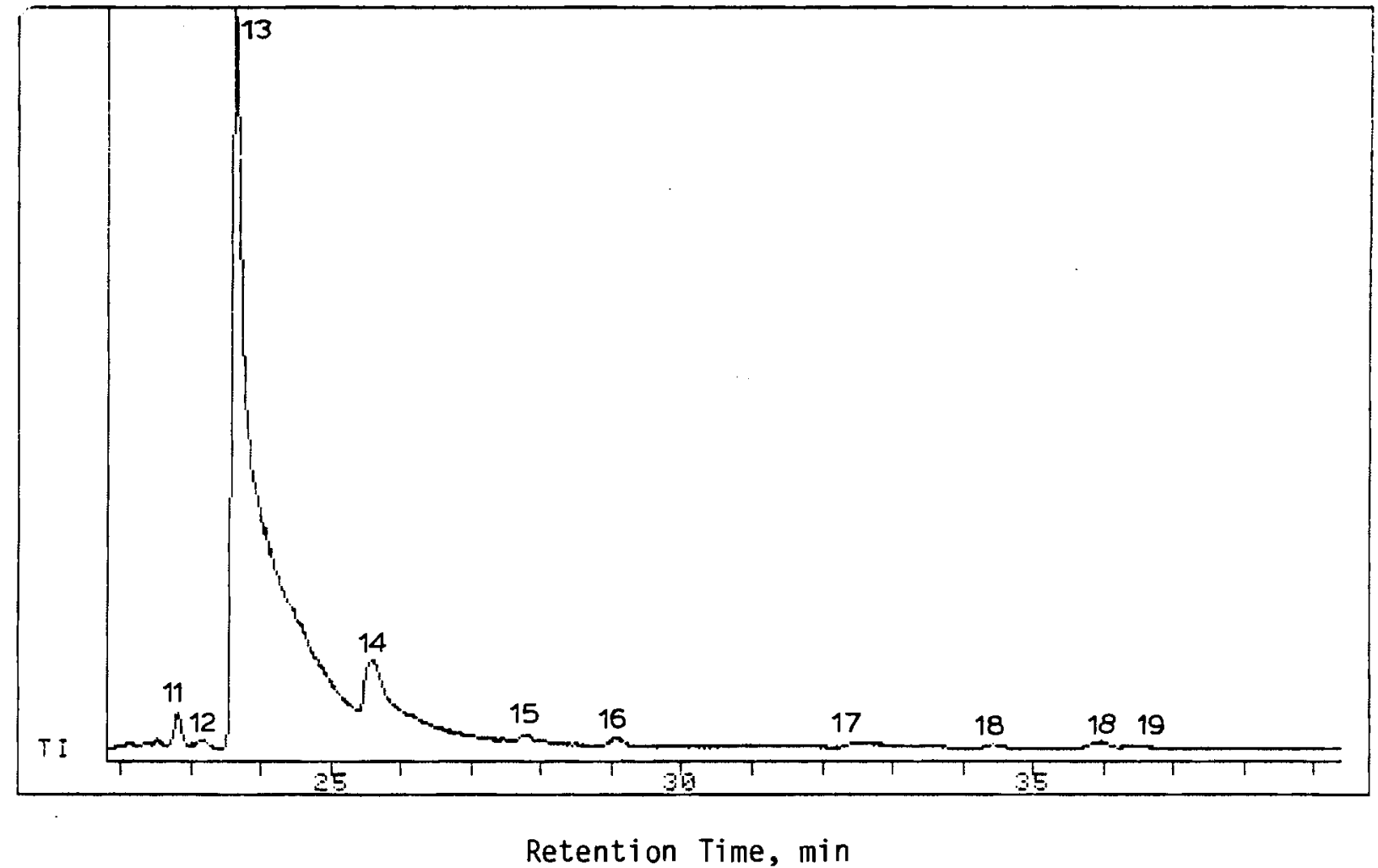

FIGURE 9. Total Ion Chromatogram for Acid Fraction of WAO Treated BGW 


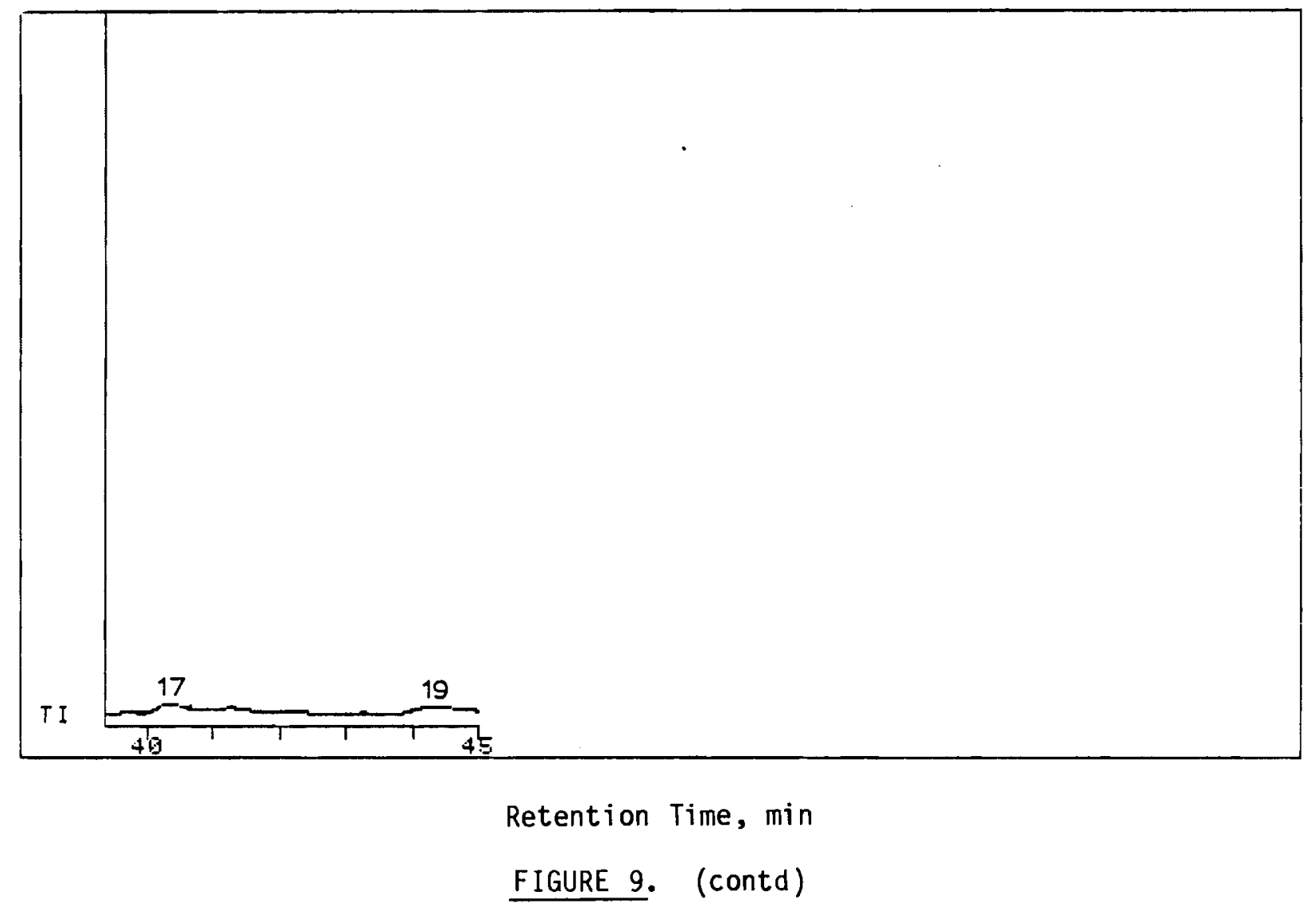


TABLE 8. Components Identified in Acid Fraction of Biological Effluent(a)

1. acetonitrile

2. toluene

3. cyclohexanediol(b)

4. alkene or alcohol (c)

5. octanoic acid

6. methylpyridinone

7. unknown, $\mathrm{M}^{+}=163$

8. tributyl phosphate (impurity)

9. nonanoic acid

10. unknown, $M^{+}=178$

11. unknown

12. decanoic acid

13. $C_{5}$-phenol

14. undecanoic acid

15. unknown

16. dodecanoic acid

17. methylbenzoic acid

18. unknown, $\mathrm{M}^{+}=154$

19. phthalate (impurity)

20. unknown, $\mathrm{M}^{+}=185$

21. aliphatic carboxylic acid

22. aliphatic carboxylic acid

23. aliphatic carboxylic acid

24. dimethylbenzebutanoic acid(c)

25. aliphatic carboxylic acid

26. unknown

27. unknown

(a) Number correspond to those in Figure 10.

(b) Very uncertain.

(c) Uncertain, but reasonably good mass spectral fit. 


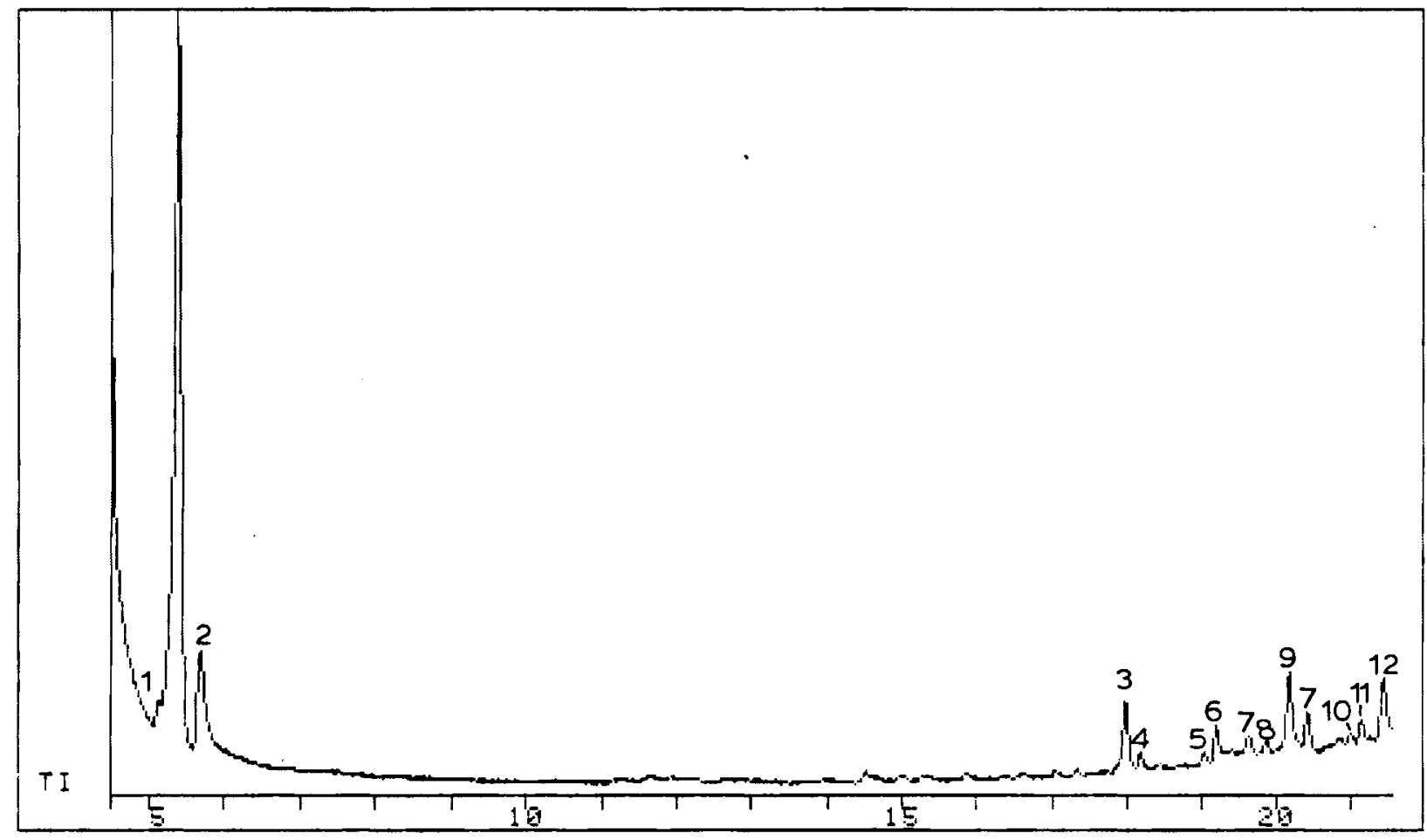

Retention Time, min

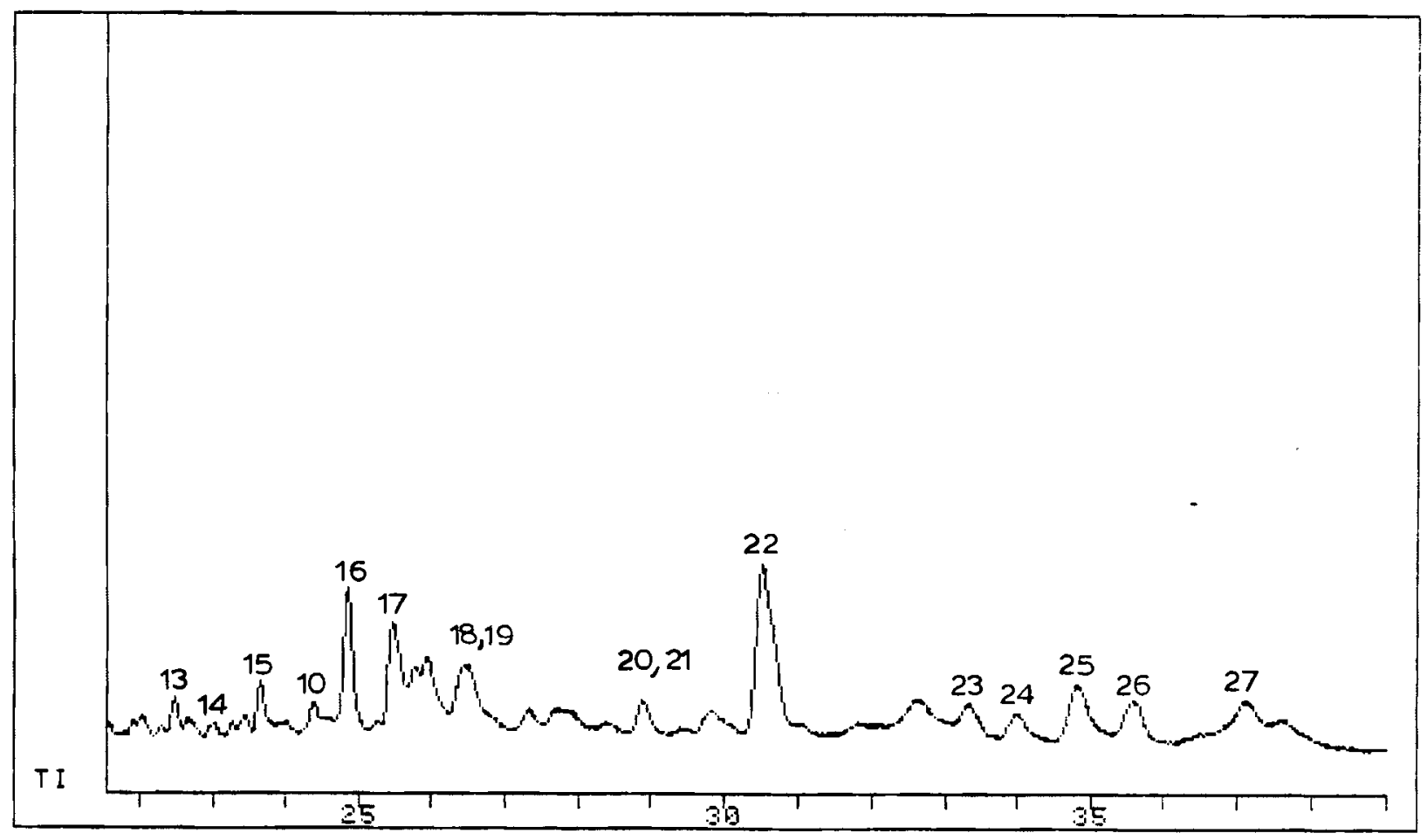

Retention Time, Min

FIGURE 10. Total Ion Chromatogram for Acid Fraction of Biological Effluent 
TABLE 9. Components Identified in Neutral Fraction of Raw BGW(a)

1. 2-furancarboxaldehyde

2. $\mathrm{C}_{7}$ cyclic ketones (dimethylcyclopentenone)

3. $C_{6}$ cyclic ketones (methylcyclopentenone)

4. benzaldehyde

5. methyl furancarboxal dehyde ${ }^{(b)}$

6. acetophenone

7. methylfuranone

8. naphthalene

9. pyranone

10. unknown

11. benzene methanol

12. benzene ethanol

13. $\mathrm{M}^{+}=164$ (b)

14. $C_{3}$-phenols

15. unknown

16. unknown

17. dihydroindenone

18. $\mathrm{M}^{+}=178(\mathrm{~b})$

19. $\mathrm{C}_{4}$-phenol

20. unknown

21. methoxy propenyl phenol(b)

22. unknown

23. dimethoxymethylphenol

24. isobenzofuranone

25. unknown

26. dimethoxyethylphenol

27. benzopyranone

28. unknown, $\mathrm{M}^{+}=178$

29. dimethoxypropenylphenol

30. unknown, $\mathrm{M}^{+}=174$

31. unknown, $\mathrm{M}^{+}=188$

(a) Numbers correspond to those in Figure 11.

(b) Uncertain, but reasonably good mass spectral fit. 

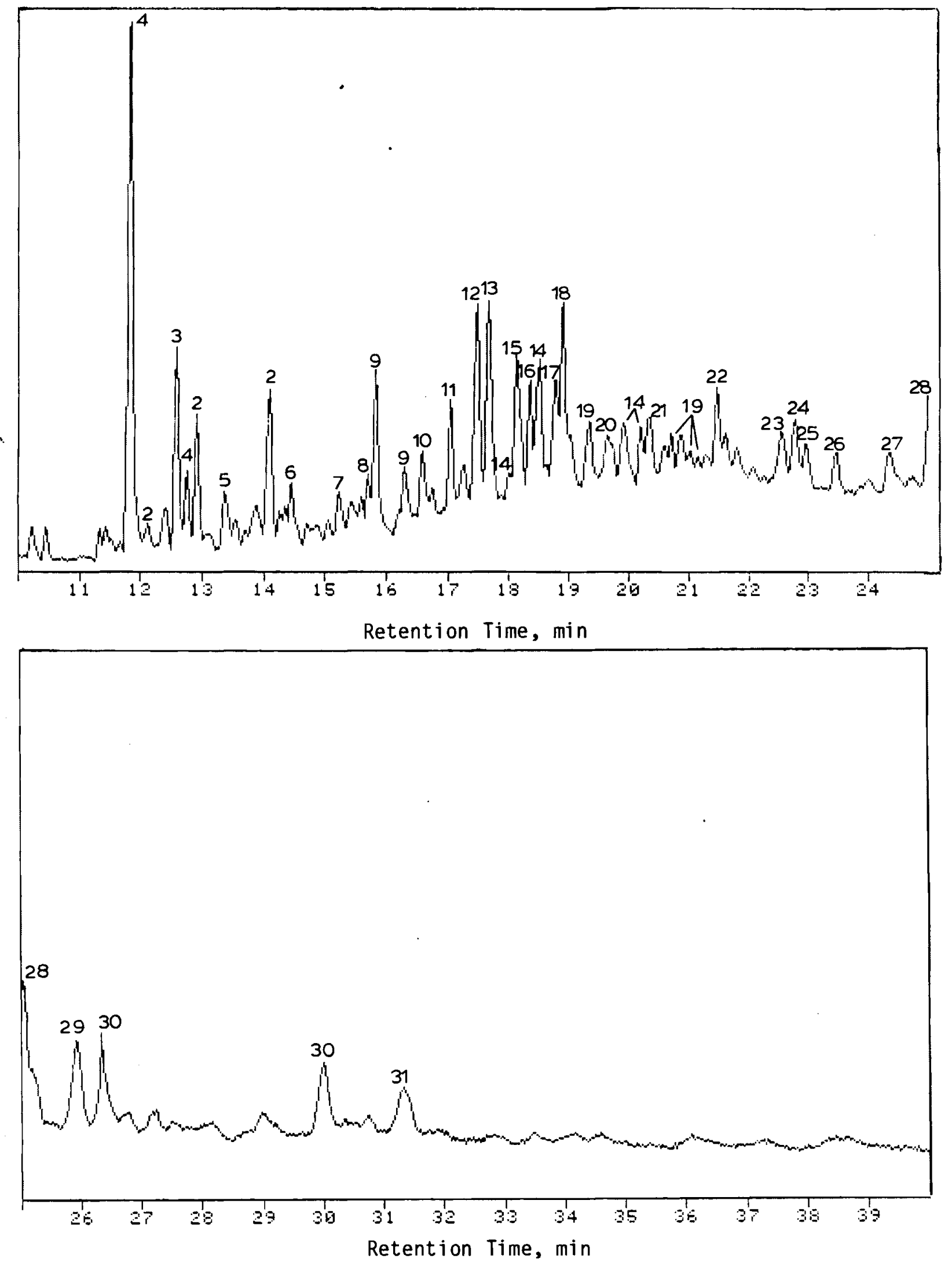

FIGURE 11. Total Ion Chromatogram for Neutral Fraction of Raw BGW 
TABLE 10. Components Identified in Neutral Fraction of WAO Treated BGW(a)

1. hydroxy methylpentanone

2. $C_{6}-$-cyclic ketone (cyclohexenone)

3. acetic acid

4. cyclohexenol (b)

5. benzaldehyde

6. acetopyridine

7. methylbenzaldehyde

8. acetophenone

9. pyridinecarboxaldehyde

10. methylpheny lethanone

11. pyridinylethanones

12. methyl pyridinylethanone or amino phenylethanone(c)

13. unknown

14. pyrrolidinone

15. dinydroindenone

16. unknown, $\mathrm{M}^{+}=163$

17. phenylbutenone $(\mathrm{c})$

18. benzenedicarboxal dehyde

19. unknown, $\mathrm{M}^{+}=177$

20. methylethyl phenylethanone (b)

21. unknown, $M^{+}=160$

22. unknown, $M^{+}=148$

23. unknown

24. isobenzofurandione

25. unknown, $M^{+}=175$

26. isobenzofuranone

27. unknown, $M^{+}=162$

28. unknown

29. benzopyranone

30. unknown

31. methylisobenzo furanone

32. unknown, $M^{+}=148$

33. benzamide

34. phenylpyridinyl methanone

35. unknown, $M^{+}=175$

36. unknown, $\mathrm{M}^{+}=181$

37 fluorenone

38. unknown

39. unknown, $M^{+}=182$

40. xanthenone

41. methylphenylpyridyl methanone

42. unknown

(a) Numbers correspond to those in Figure 12.

(b) Very uncertain.

(c) Uncertain, but reasonably good mass spectral fit. 


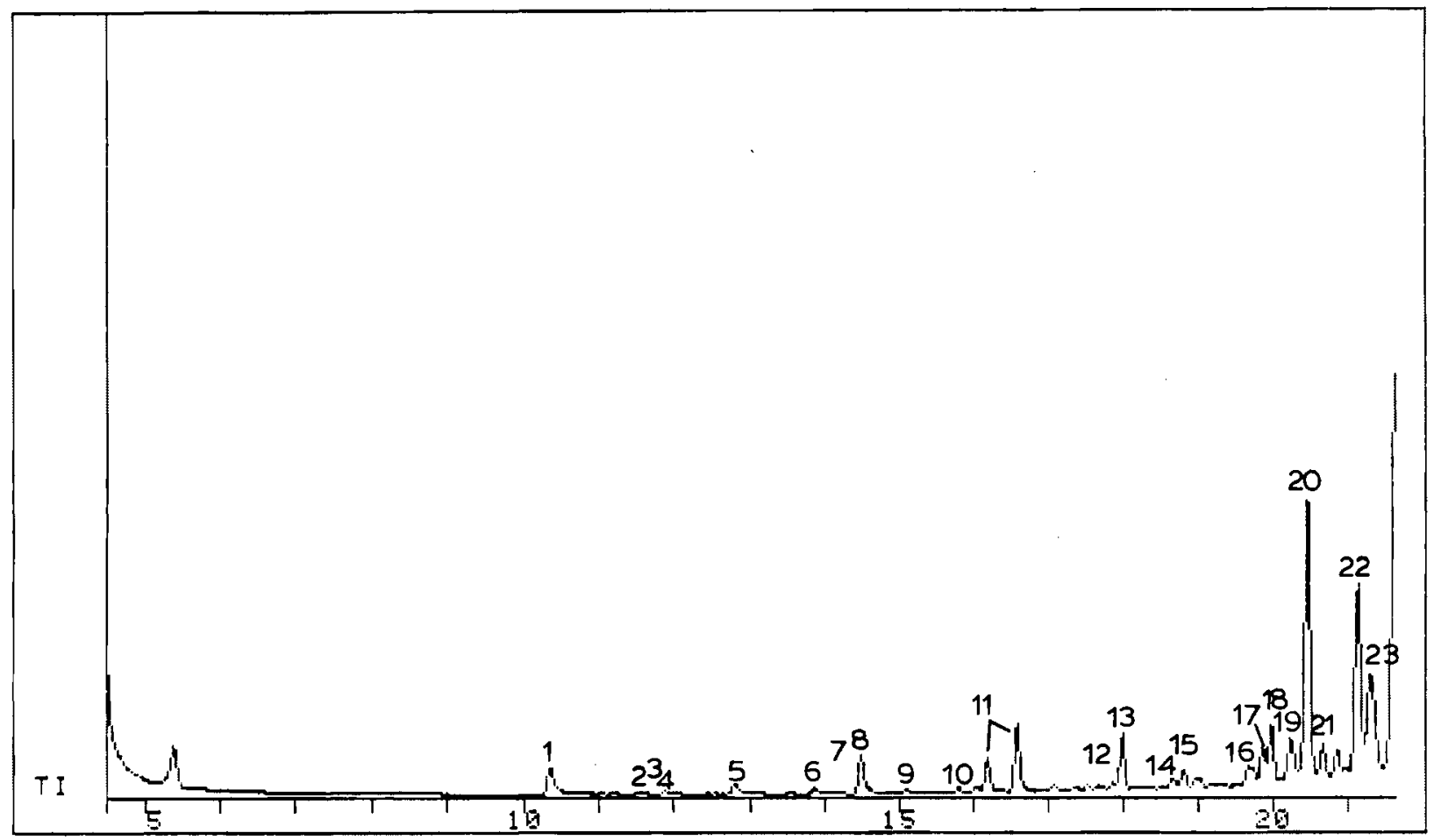

Retention Time, min

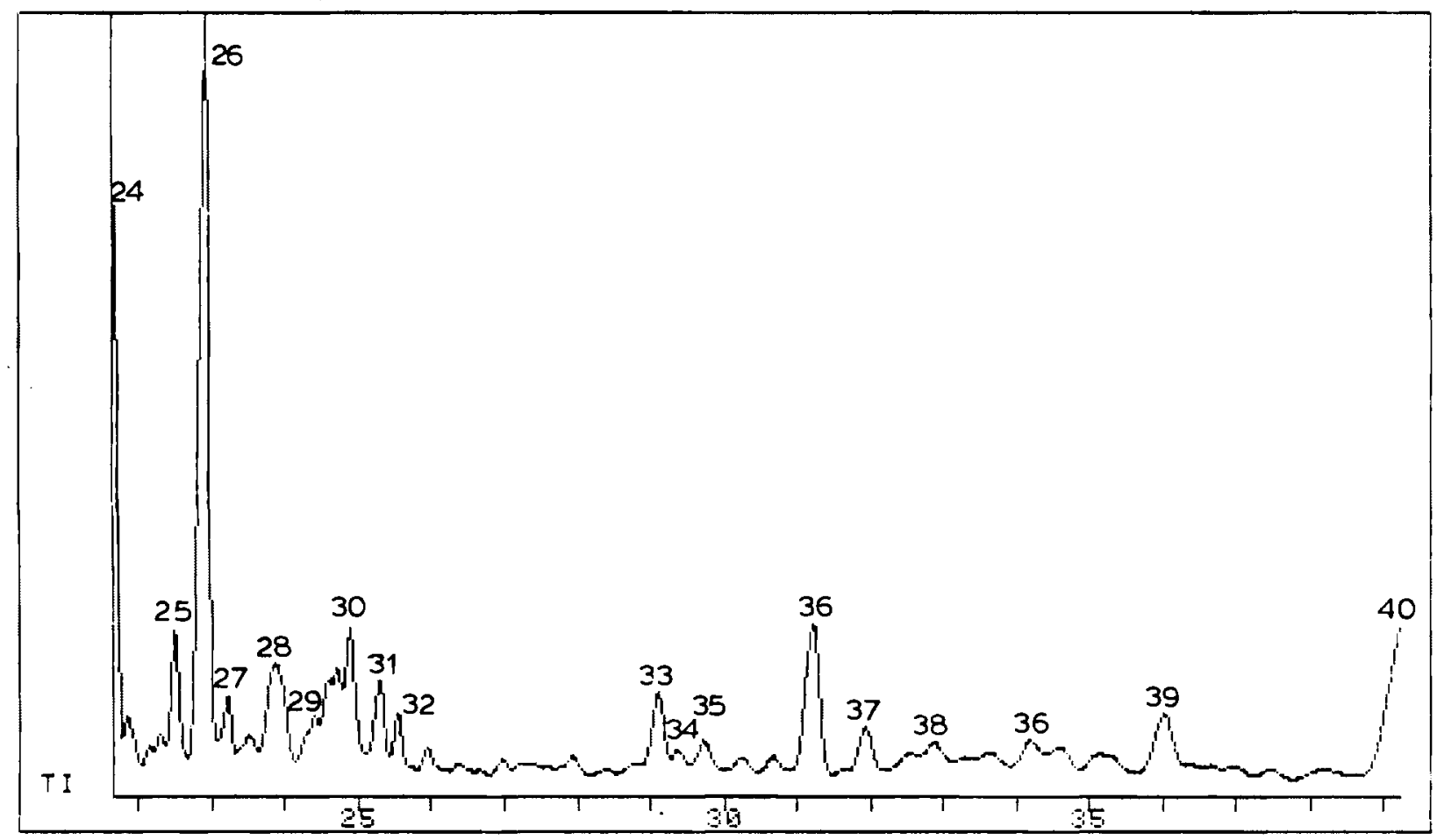

Retention Time, min

FIGURE 12. Total Ion Chromatogram for Neutral Fraction of WAO Treated BGW 


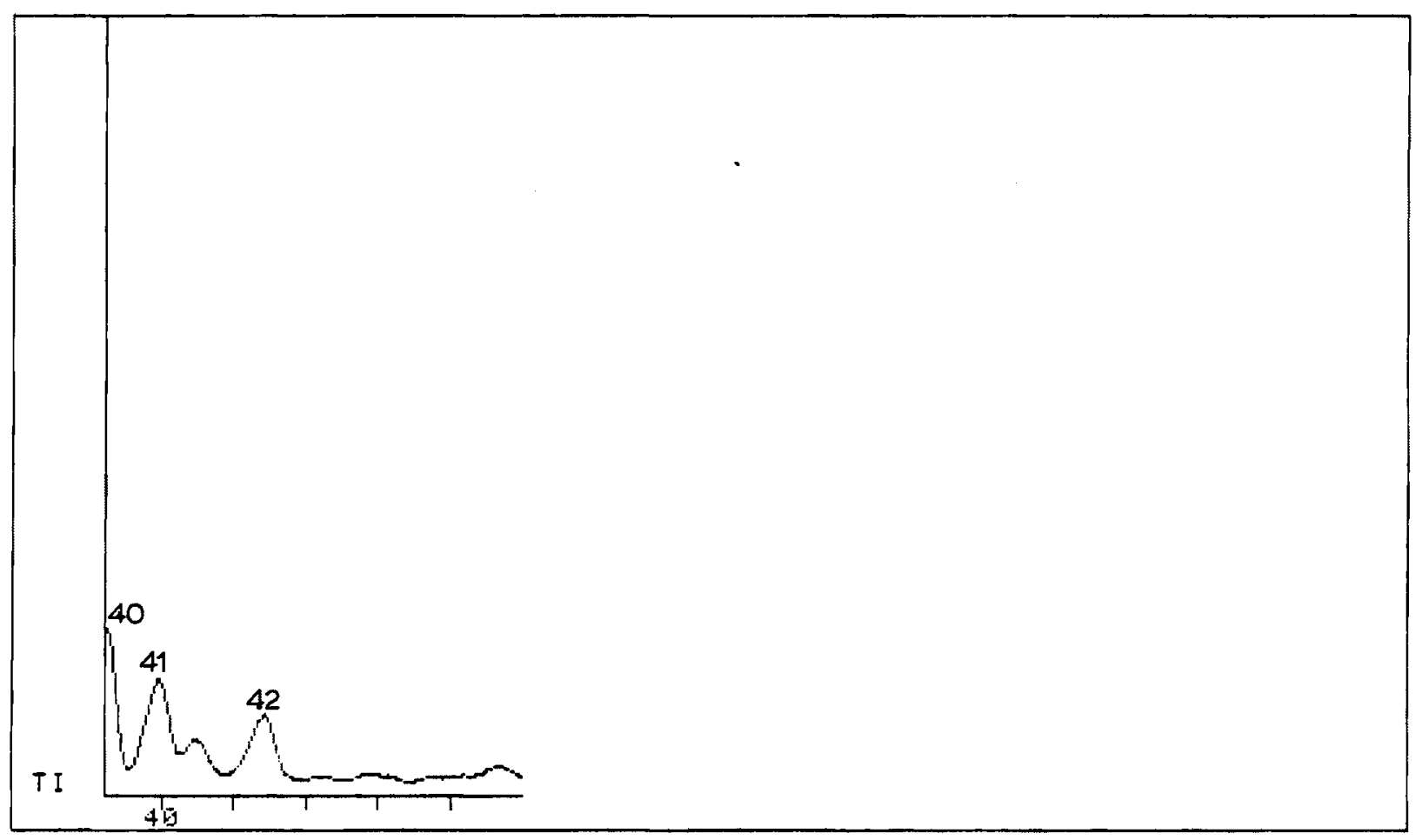

Retention Time, min

FIGURE 12. (contd) 
TABLE 11. Components Identified jn Neutral Fraction

1. alkanes

2. aliphatic carboxylic acids

3. tributyl phosphate

4. unknown, $M^{+}=148$

5. ethyl phthalate

6. alkene or alcohol

7. unknown, $M^{+}=160$

(impurities)

8. butyl phthalate

9. phthalates

10. unknown, $\mathrm{M}^{+}=146$

11. unknown, $M^{+}=181$

12. unknown, $M^{+}=147$

13. unknown, $M^{+}=182$

(impurity)

(impurity)

(impurity)

(impurity)

(impurity)

(impurity)

(impurity)

(impurity)

(impurity)

(a) Numbers correspond to those in Figure 13. 


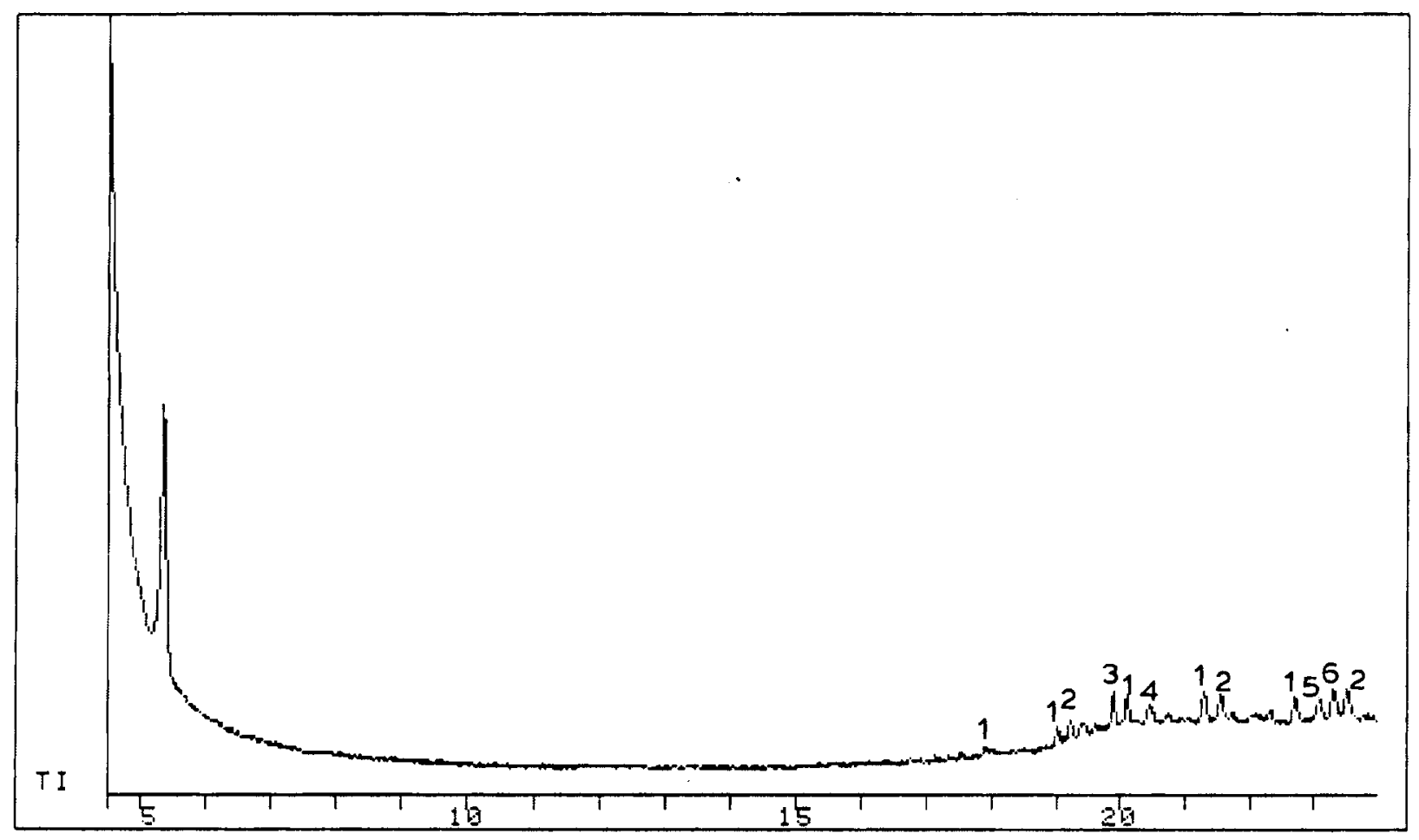

Retention Time, min

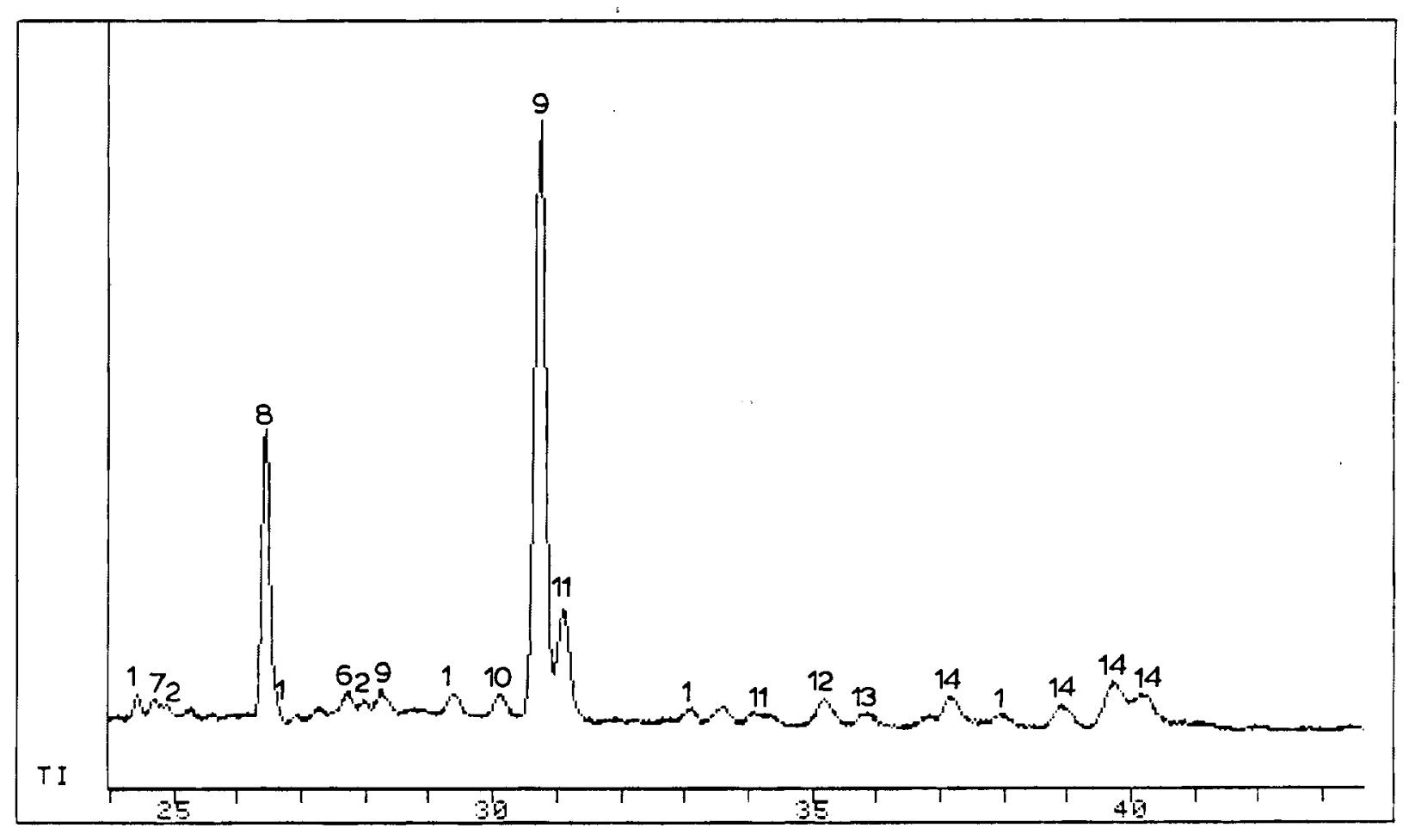

Retention Time, min

FIGURE 13. Total Ion Chromatogram for Neutral Fraction of Biological Effluent 


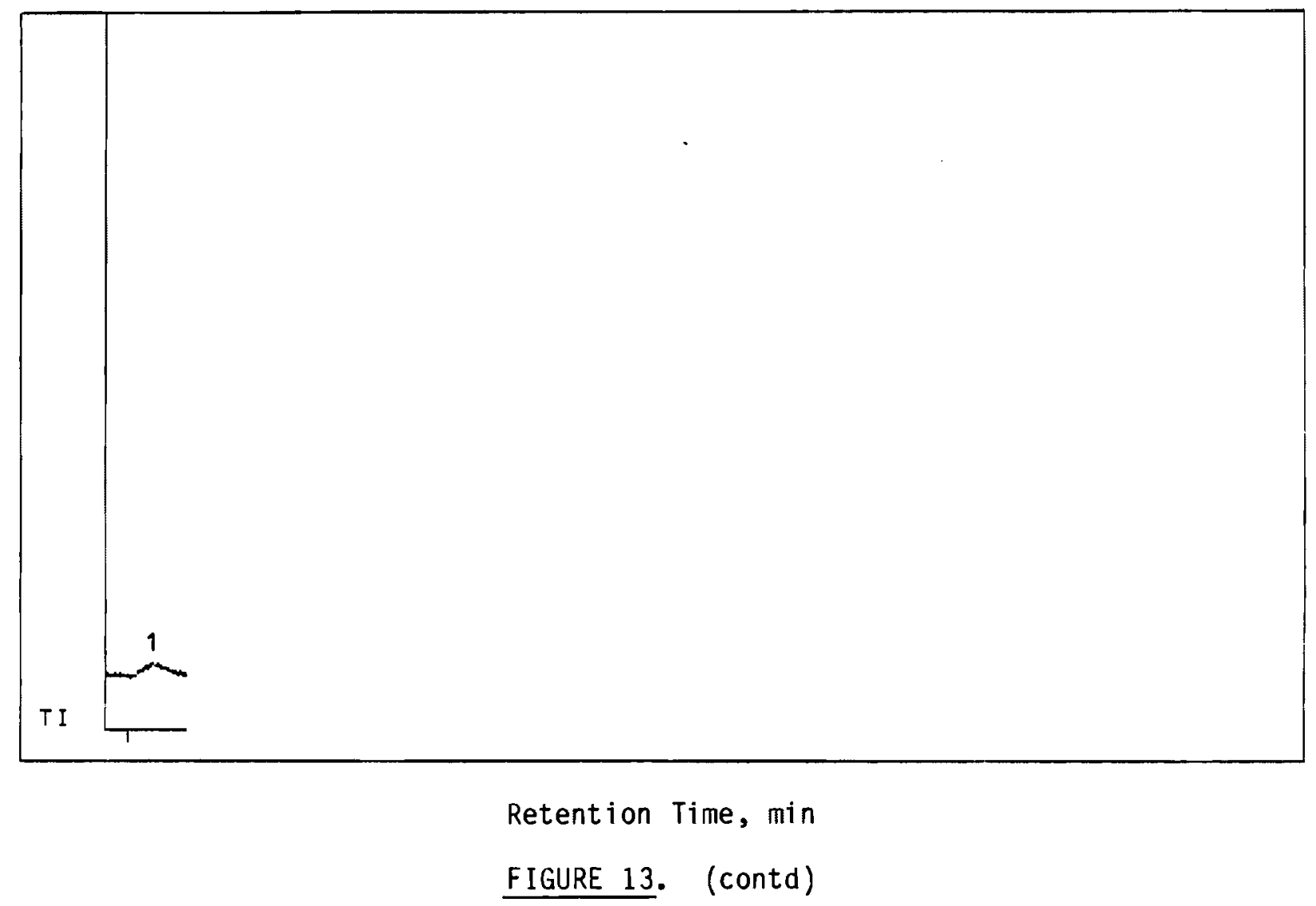


TABLE 12. Components Identified in Basic Fraction of Raw BGW(a)

1. pyridine

2. methylpyridipe

3. furandione $b$

4. furaldehyde

5. ethylpyridine

6. pyranone

7. phenol

8. dihydroxymethylpenzene $(c)$

9. benzotriazole $(c)$

10. unknown

11. benzoxazole (b)

12. methyiphenols

13. naphthalenol (b)

14. quinoline

15. iosquinoline

16. indazole (b)

17. methylquinolines

18. $C_{2}$-quinolines

19. $C_{2 \text {-singly unsaturated quinolines }}^{(b)}$

20. unknown

21. phthalate

22. alkyl and phthalate impurities

(a) Numbers correspond to those in Figure 14.

(b) Uncertain, but reasonably good mass spectral fit.

(c) Very uncertain. 


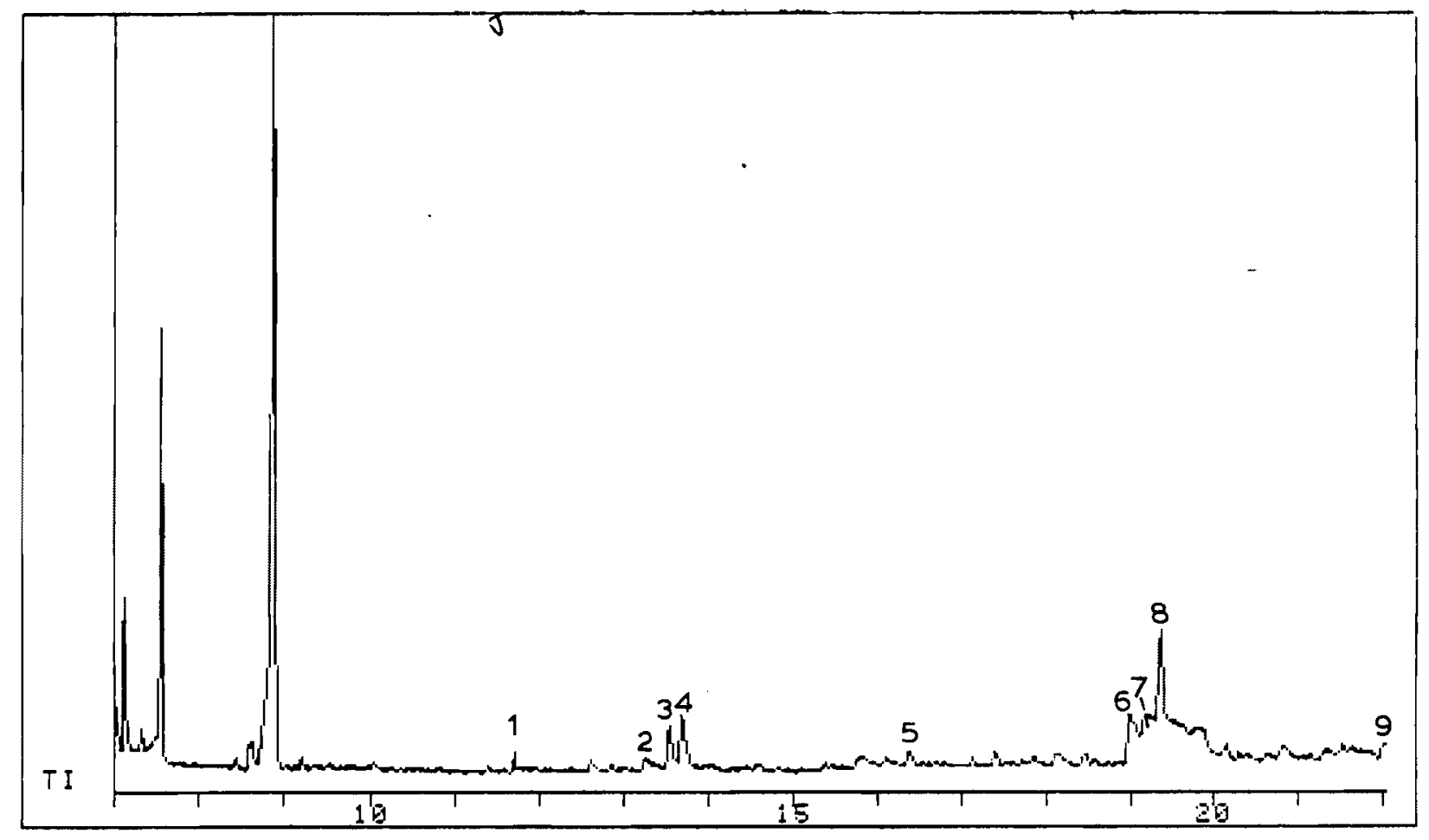

Retention Time, min

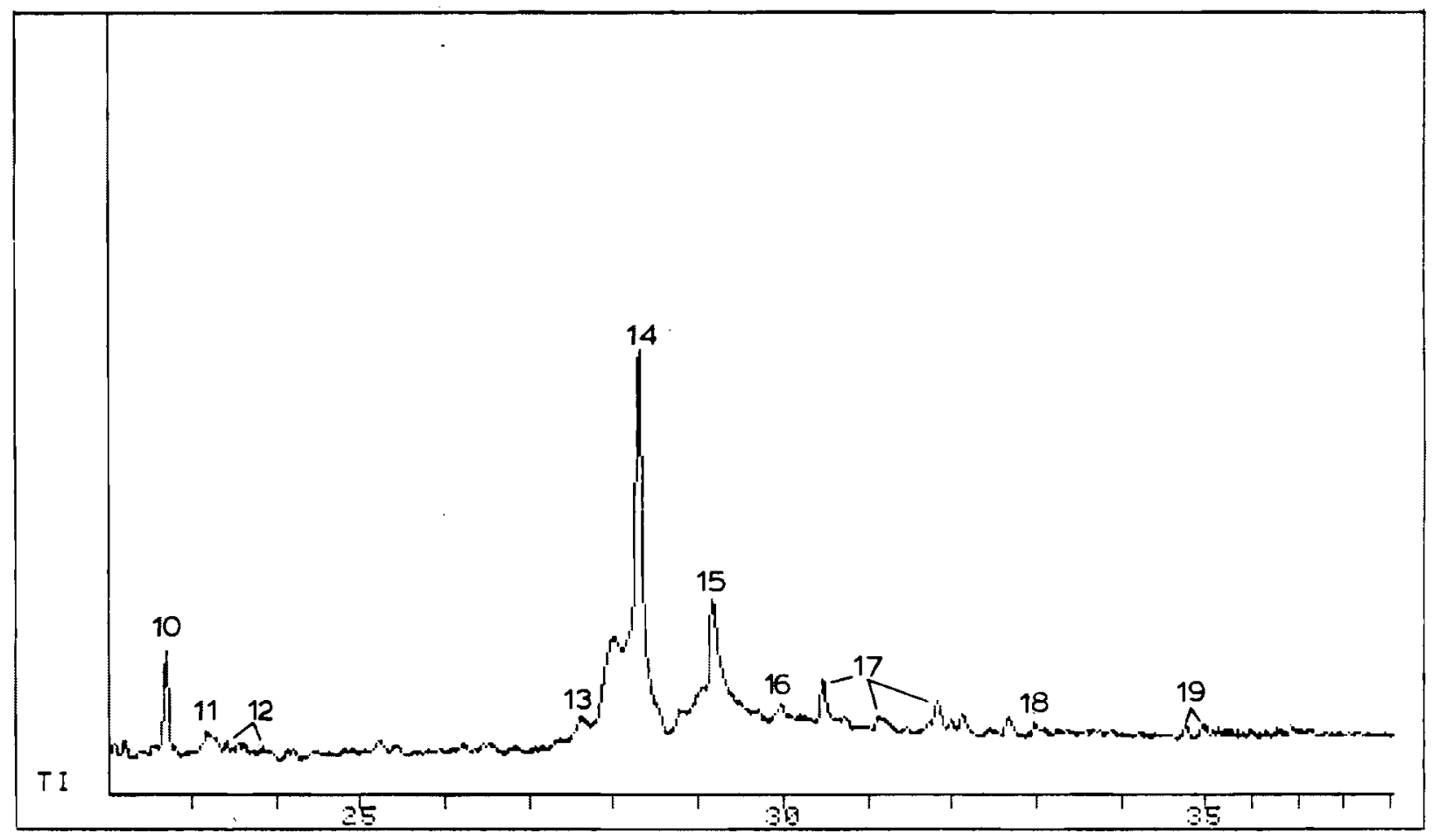

Retention Time, min

FIGURE 14. Total Ion Chromatogram for Basic Fraction of Raw BGW 


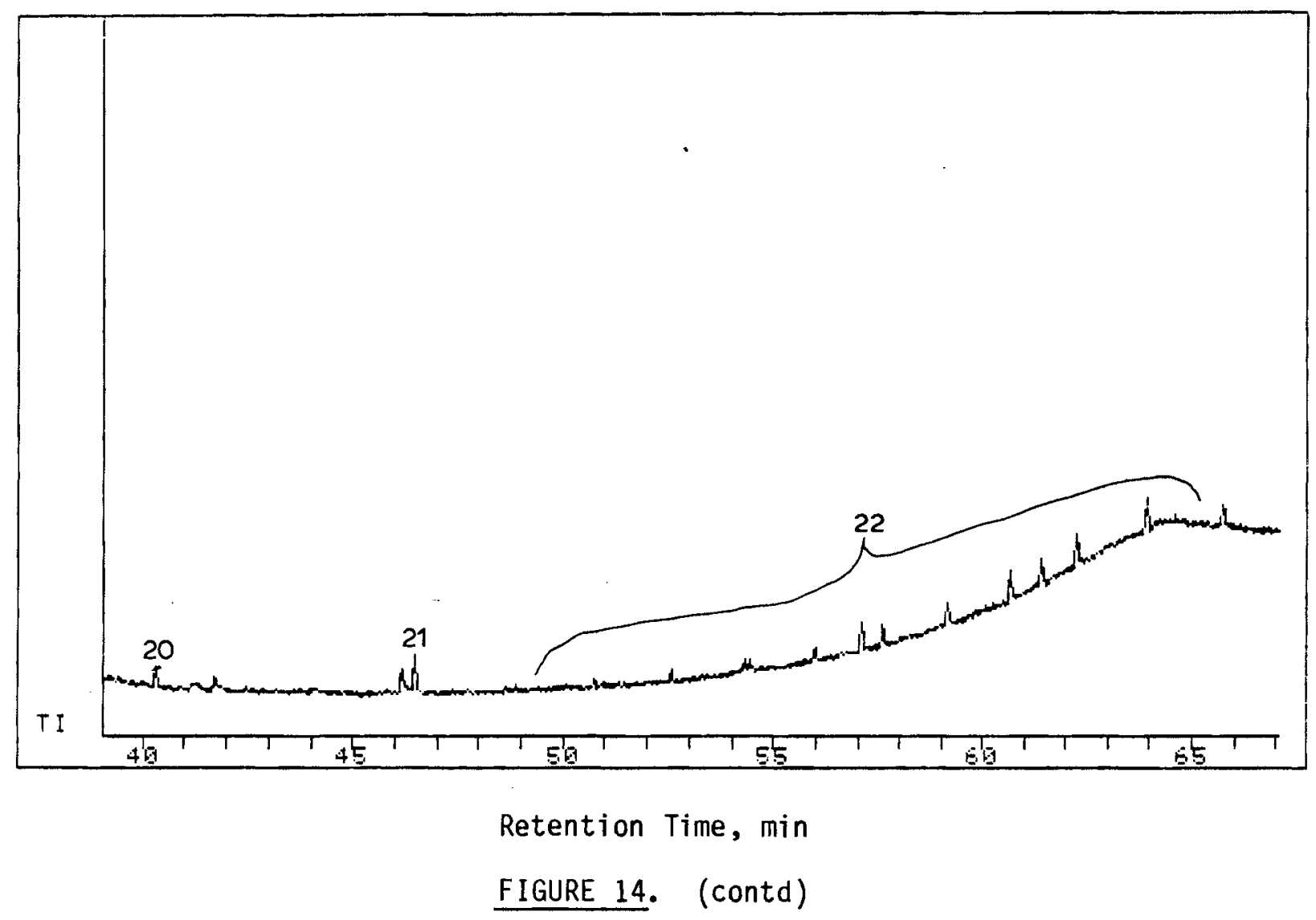


TABLE 13. Components Identified in Basic Fraction of WAO Treated BGW(a)

1. pyridine carboxylic acid(b)

2. benzaldehyde

3. pyridine carboxaldehydes

4. C 3 -pyridine

5. pyrrolidinone (b)

6. pyridinylethanones

7. unknown, $M^{+}=132$

8. methylpyridipylethanones (b)

9. pyridinone $(b)$

10. oxide-methylpyridines (b)

11. quinoline

12. unknown, $M^{+}=122$

13. isoquinoline

14. naphthyridine

15. unknown, $M^{+}=122$

16. dihydroindolone (b)

17. methylquinolines

18. benzamide

19. methyl tetrahydroquinol ines (b)

20. methylnaphthyridines

21. pyridinecarboxamides (b)

22. $C_{2}$-tetrahydroquinoline (b)

23. bipyridines

24. ethenylquinolines (b)

25. methyldihydroindole (c)

26. $C_{3}$-singly unsaturated quinolines or dipyridopyrroles $(b)$

27. biphenylol(b)

28. methylbenzopyranone (b)

29. unknown, $M^{+}=170$

30. unknown, $M^{+}=172$

31. phenylpyridinyl methanone

32. unknown

33. dipyridylmethanones (b)

34. N-phenylmethylbenzenemethanamine

35. N-pheny lmethyl enebenzenemethanamine

36. unknown, $M^{+}=182$

37. unknown, $M^{+0}=181$

38. unknown, $M^{+0}=198$

39. methoxydibenzofuran (c)

40. pyranoi soquinolinone (or isomer) (b)

41. unknown, $M^{+}=225$

42. unknown, $M^{+}=211$

43. unknown, $M^{+}=210$

44. $C_{16}$-singly unsaturated hydrocarbon

(impurity)

(impurity)

(impurity) 
TABLE 13. (contd)

45. unknown

46. phthalate

47. alkyl and phthalate impurities

(impurity)

(a) Numbers correspond to those in Figure 15.

(b) Uncertain, but reasonably good mass spectral fit.

(c) Very uncertain. 


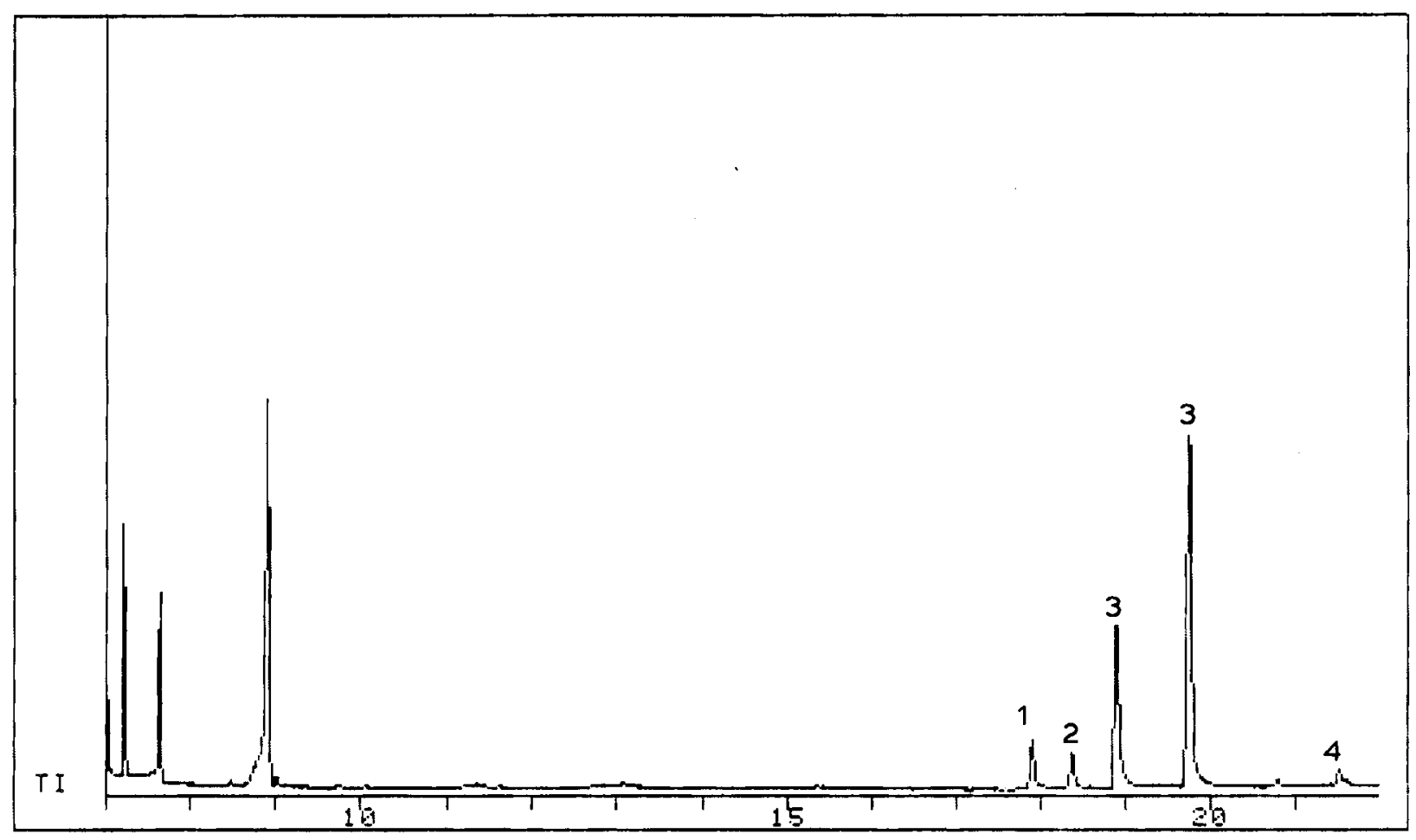

Retention Time, min

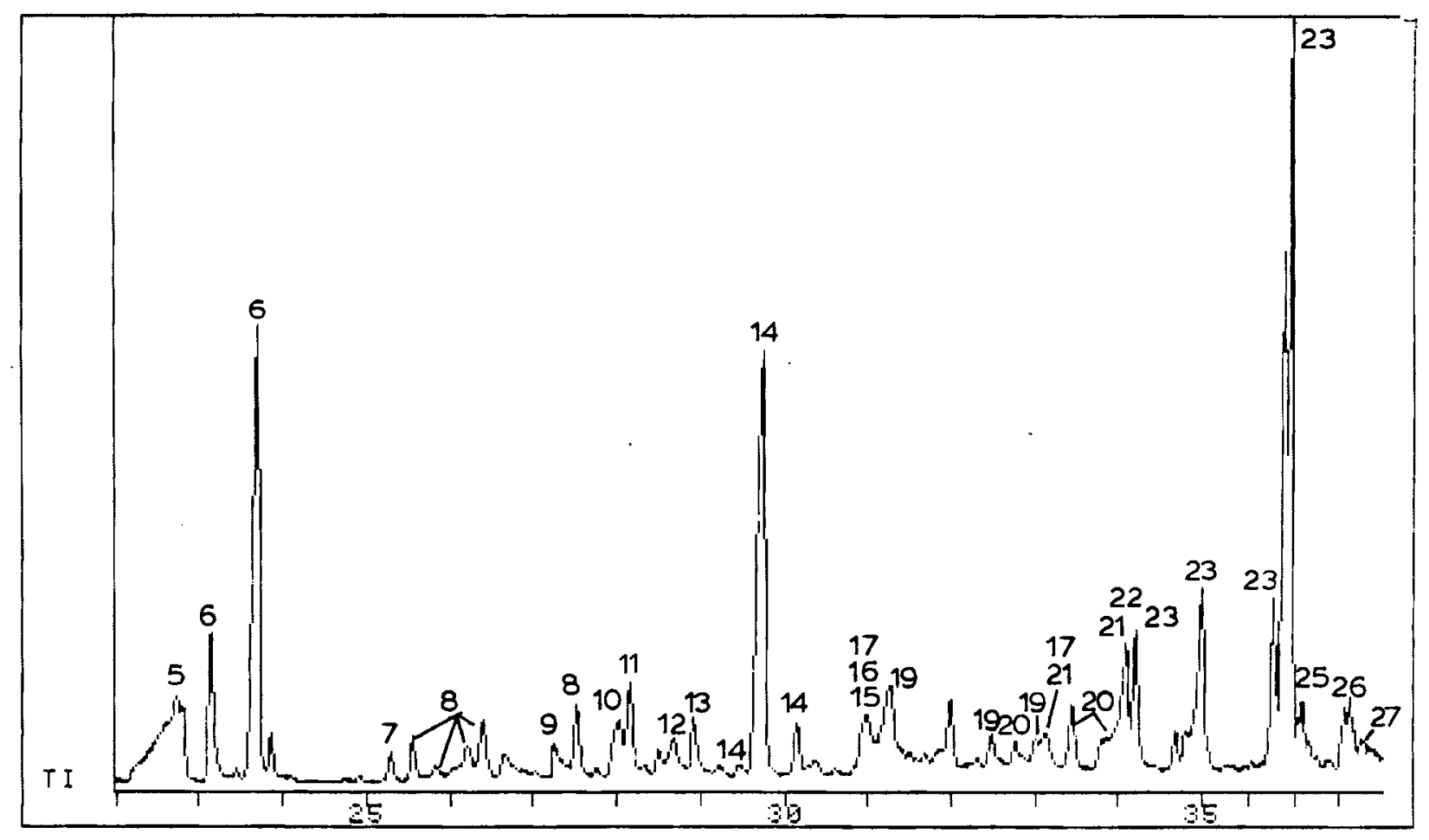

Retention Time, min

TABLE 15. Total Ion Chromatogram for Basic Fraction of WAO Treated BGW 


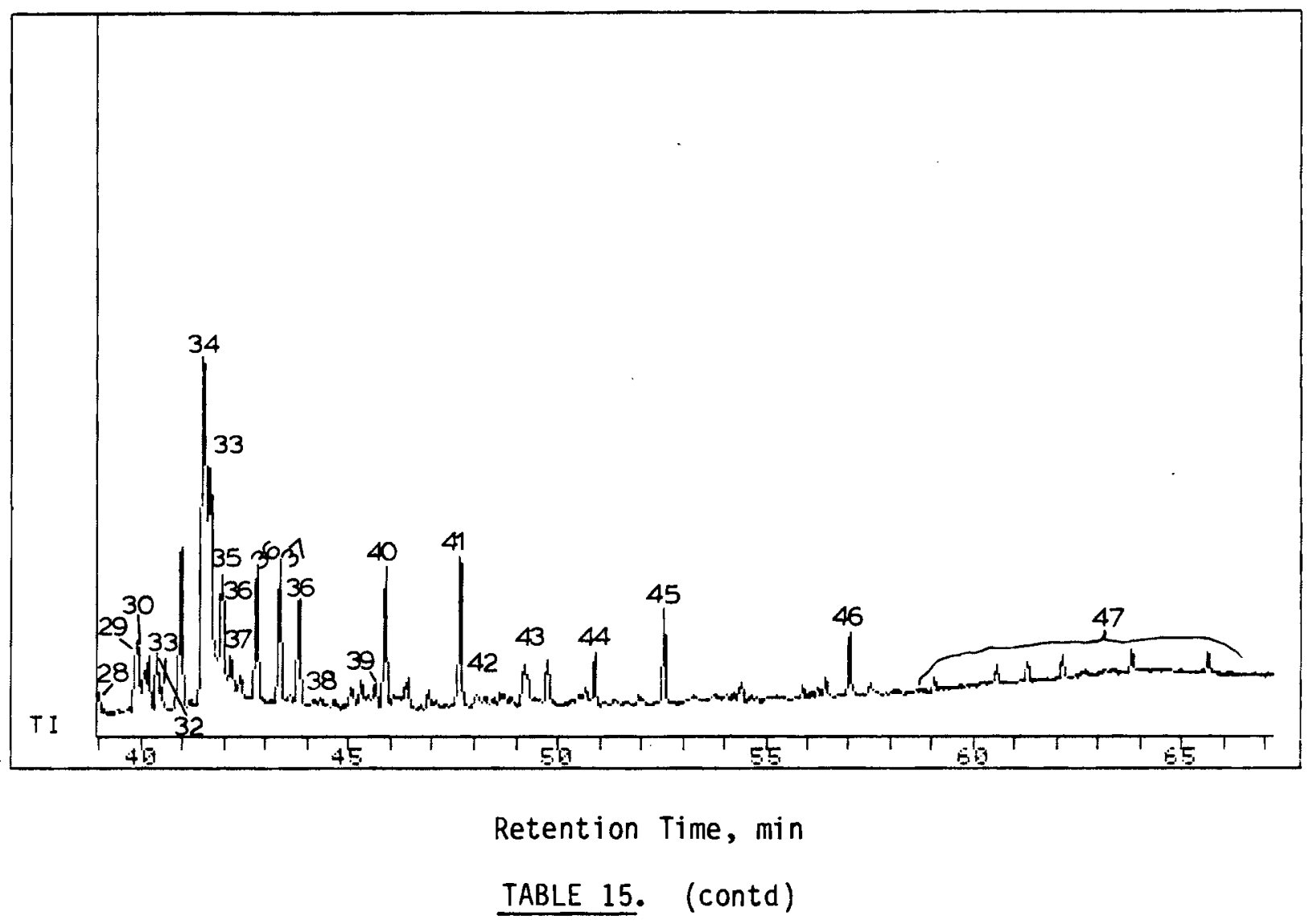


TABLE 14. Components Identified in Basic Fraction of Biological Effluent(a)

1. unknown

2. benzaldehyde

3. pyridinylethangne ${ }^{(b)}$

4. benzothiazole $(b)$

5. carboxylic acid

6. unknown, $\mathrm{M}^{+}=140$

(impurity)

7. naphthyridines

8. methylpyrrolidinyl pyridine(b)

9. unknown, $\mathrm{M}^{+}=149$

10. N-nmethylpyridine carboxamide(b)

11. bipyridines

12. $C_{3}$-singly unsaturated quinolines or dipyridopyrrole(b)

13. biphenylols $(\mathrm{b})$

14. unknown, $\mathrm{M}^{+}=148$

15. unknown, $M^{+}=160$

16. phenylpyridinylmethanone

17. methylbenzopyranone

18. benzimidazole carboxaldehyde

19. N-phenylmethylbenzenemethanamine $(c)$

20. unknown, $M^{+}=182$

21. unknown, $\mathrm{M}^{+}=181$

22. pyraniosoquinolinones (or isomer) (b)

23. C 16 -carboxylic acid

24. phthalate

25. unknown, $M^{+}=225$

26. unknown

27. C 18 -carboxylic acid

28. atkene

29. unknown

30. unknown

31. alkene

32. phthalate

33. alky1, phthalate impurities

(impurity)

(impurity)

(impurity)

(impurity)

(impurity)

(impurity)

(impurity)

(impurity)

(a) Numbers correspond to those in Figure 16 .

(b) Uncertain, but reasonably good mass spectral fit.

(c) Very uncertain. 


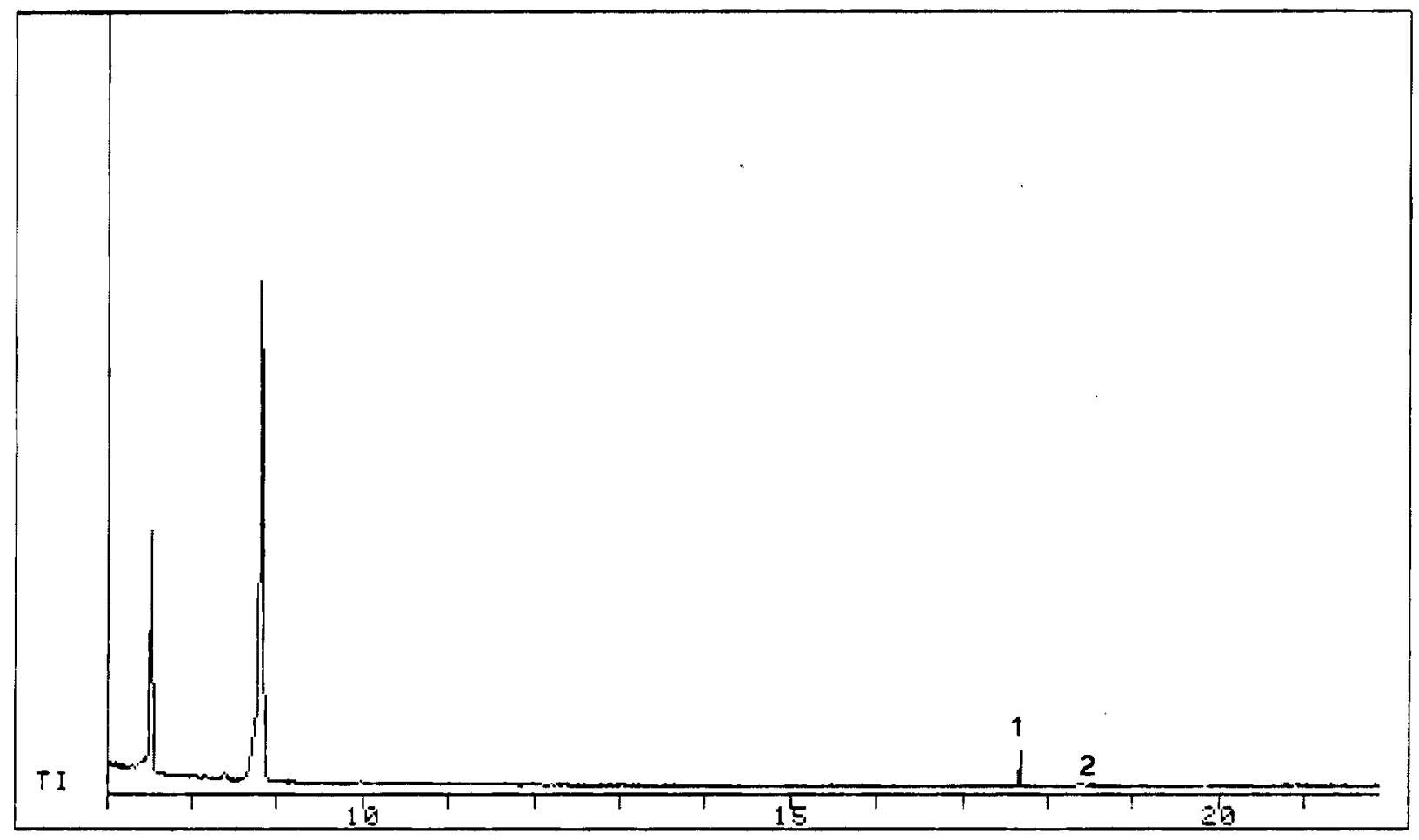

Retention Time, min

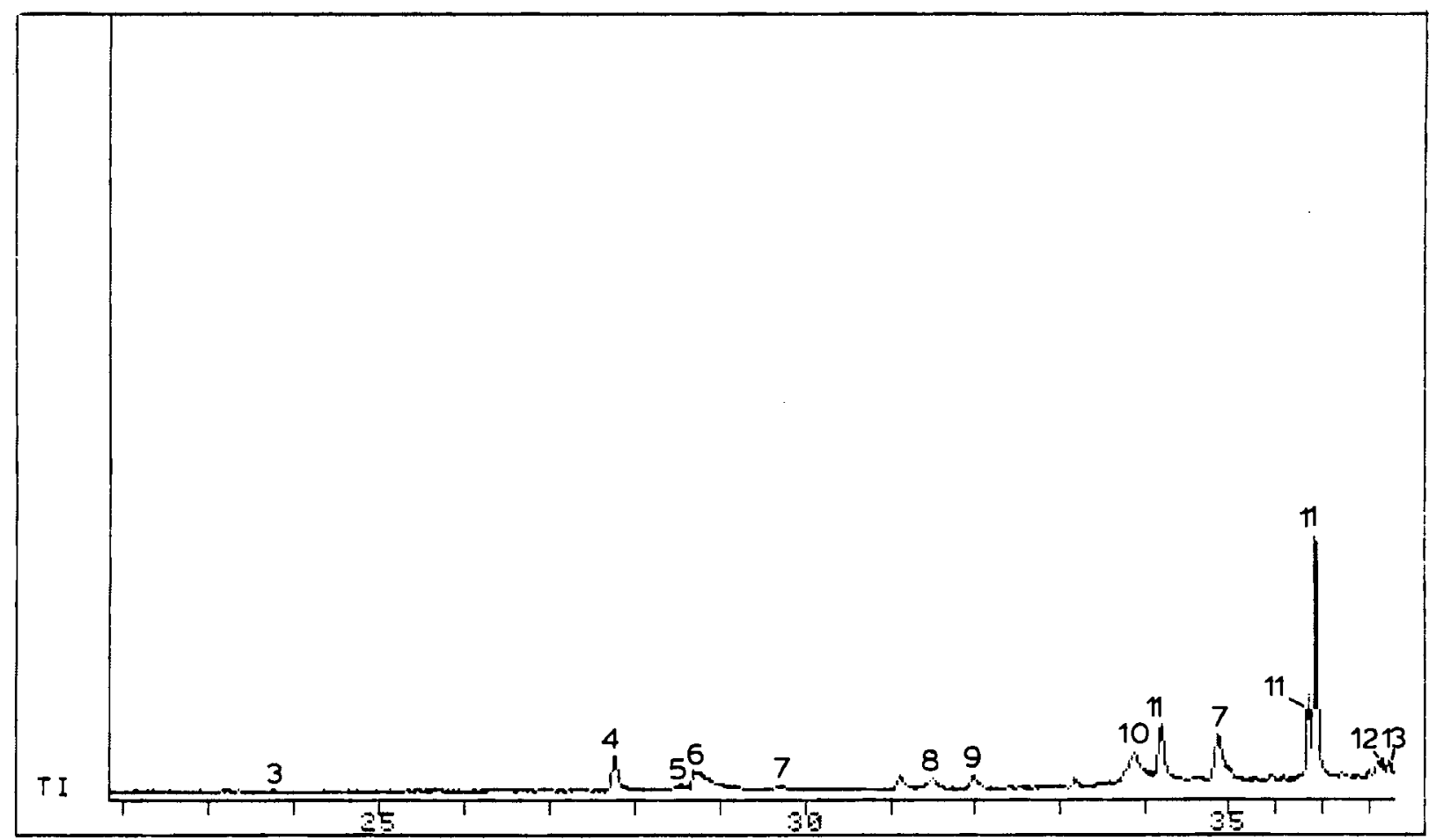

Retention Time, min

FIGURE 16. Total Ion Chromatogram for Basic Fraction of Biological Effluent 


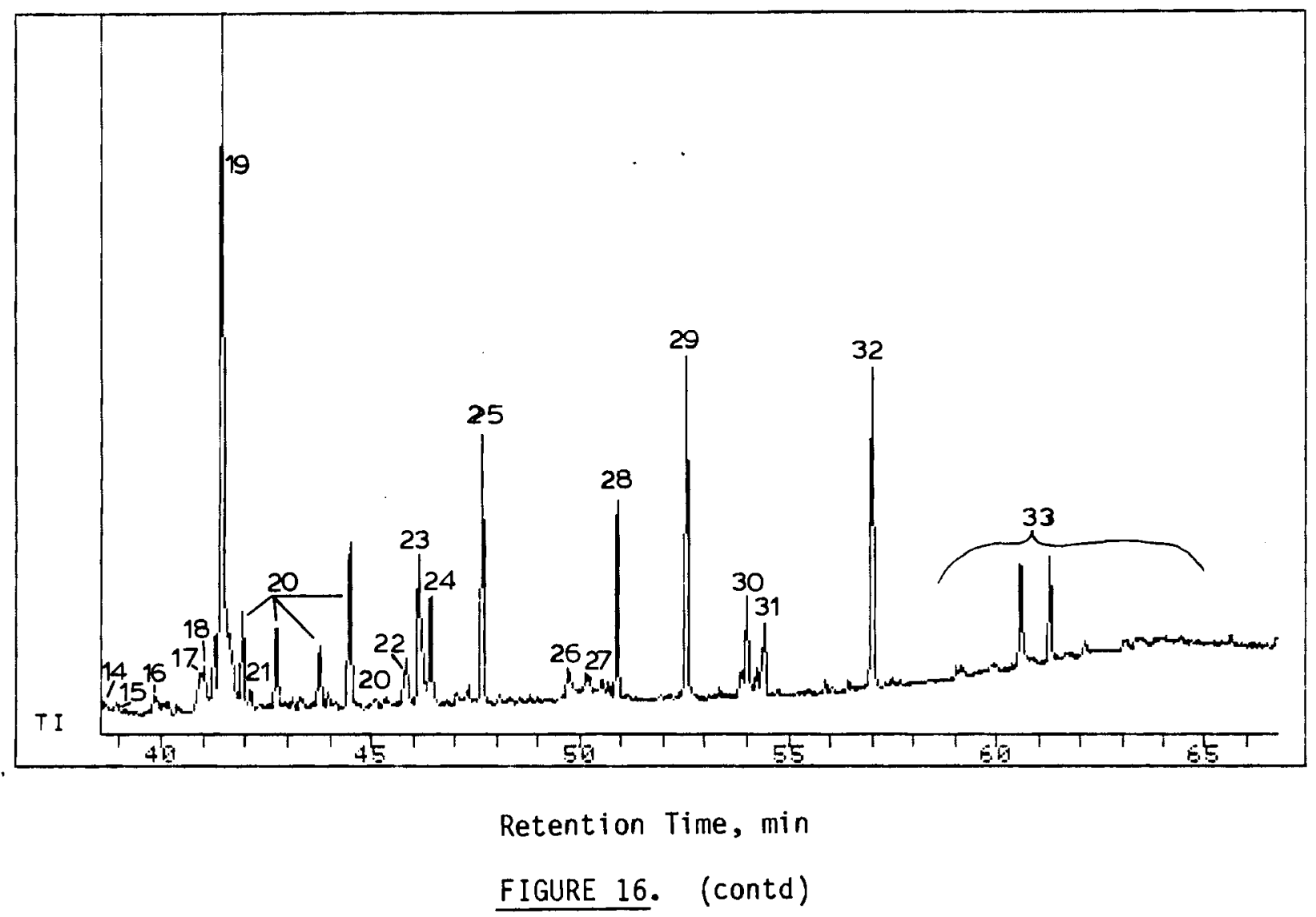

1 


\section{$\underline{\text { DISCUSSION }}$}

CHEMICAL CHARACTERISTICS OF RAW BGW

The compounds identified by GC/MS in extract of the raw wastewater consisted of predominantly alkylphenols and methoxyphenols. Aromatic aldehydes, furans, aliphatic cyclic ketones and aromatic ketones were also present in (relatively) significant quantities in the acid and neutral fractions. The phenols and ketones are typical of biomass products and have frequently been seen in the biomass oils as well as in lignin degradation products. The furans are typical of cellulose (and biomass) degradation products.

The basic fraction of the raw BGW was relatively minor, being only $2 \%$ of the total extractable organics. This fraction is often important, however, since it contains many of the more toxic or inhibitory organics. The basic components identified in the raw wastewater consisted mainly of alkylquinolines and some pyridines. The presence of minor amounts of acidic components in the basic fraction indicating overlap in the procedure seems to be typical of acidbase extractions.

It should be noted that since all fractions were taken to dryness, volatile components were lost or depleted. Highly water soluble components (e.g., low molecular weight acids and dibasic acids) may not have been extracted by this procedure.

WET AIR OXIDATION

Wet oxidation treatment resulted in the virtual disappearance of the alkyl - and methoxyphenols from the extracted acid fractions. Benzoic acid is instead the overwhelmingly dominant peak in the chromatogram. Aromatic ketones, aldehydes, and their hydroxy derivations as well as their nitrogencontaining derivatives are present in minor amounts. Aromatic ketones and aldehydes, including the oxygen- and nitrogen-heterocyclic derivatives, predominate in the neutral fractions and do not appear to have been affected by the oxidation to the same extent as the phenols. (Since quantitative analysis was not attempted, it is not possible to determine relative amounts of the ketones and aldehydes in the raw and treated waters.) 
The basic fraction of the wet oxidation treated waters contains predominantly oxidized nitrogen heterocyclics and condensed nitrogen heterocyclics. It is not known if the acid-base procedure catalyzed the condensation of the oxidized nitrogen heterocycles creating procedural artifacts or if these components were produced by the wet oxidation treatment.

The amount of organics extracted from the WAO treated water was only $3 \%$ of the amount extracted from the raw water. This $97 \%$ reduction is substantially greater than the $74 \%$ COD reduction achieved. This indicates a relatively greater proportion of non-extractable organics in the treated water. The distribution of fractions was approximately the same as for the raw water.

BIOLOGICAL TREATMENT

Composition of Effluent

Biological treatment resulted in the loss of many of the components in the acid and neutral fractions from the wet oxidation treatment. The resulting relatively weak chromatograms contain mainly aliphatic carboxylic acids, alkanes, and phthalates, many of which may be considered impurities. Biological treatment did not appear to be as effective with the basic components. Many of the nitrogen heterocyclic ketones and condensed nitrogen heterocycles remain, although their absolute amounts appear to have decreased.

The removal of COD during the biological treatment was slightly higher than the removal of extractable organics. This indicates a slightly lower proportion of nonextractables in the biological effluent. Again, the distribution of the fractions remained approximately the same as for the raw and WAO treated waters.

\section{Performance of Reactors}

In general, the biological reactors operated quite well, achieving excellent $C O D$ removals with a relatively high strength wastes. Periods of reactor upset, noted by rising effluent $C O D$ and falling MLVSS appear to be 
related to changes in feed. Very stable operation was observed during the final five weeks of operation when a steady supply of $300^{\circ} \mathrm{C}$ treated $\mathrm{BGW}$ was available and a constant SRT of 20 days was maintained. Earlier, higher SRTs had been used during times of suspected upset to maintain MLVSS levels.

The major difficulty encountered during operation was the formation of bulking sludge caused by filamentous bacteria. Sludge bulking would occasionally plug the reactors, stopping circulation of contents. Mechanical agitation was necessary to disperse the sludge. This problem seemed to alleviate itself as the SRT was lowered.

Final operating conditions for reactors 1 and 2, respectively, were

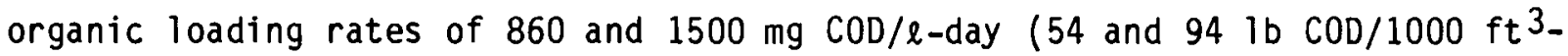
day), MLVSS of 2600 and $3700 \mathrm{mg} / \ell$, SRT of 19 and 20 days, and HRT of 10 and 6.7 days. Typical values for conventional activated sludge treatment of sewage are 460-920 mg COD/ $\ell$-day (30-60 lb COD/1000 $\mathrm{ft}^{3}$-day), 2000-4000 mg/ $/$ MLVSS, 515 days, and 4-8 hr, respectively (Metcalf and Eddy 1972). The high value of HRT in this study was necessitated by the high feed strength. Otherwise, it appears that wet oxidized BGW could be treatable by conventional activiated sludge technology. The effluent COD levels achieved in this study, 200$400 \mathrm{mg} / \mathrm{l}$, would probably be suitable for discharge to a municipal treatment plant. Quantitative chemical analysis would be necessary to assure that priority pollutants (e.g., phenol, toluene) were not present in levels above criteria (45 FR 231).

The results also indicate that aerobic treatment using even higher organic loading rates should be possible. This would mean that smaller, more economical aeration basins could be used. Possible limitations to higher loading rates are aeration capacity and sludge settling problems resulting from higher MLVSS levels.

An especially encouraging result of the study was the ease with which the biological reactors were acclimated to the full strength feed. This occurred much more easily than in previous studies with BGW that had not been pretreated. This seems to be due to the difference in chemical characteristics between the raw and treated waters. This might prove especially beneficial for anaerobic treatment. In previous studies, anaerobic systems could not be 
acclimated to full strength BGW because of apparent toxicity problems. Anaerobic treatment is well suited for lower molecular weight acids and would probably do quite well with wet oxidized BGW. An advantage is that is does not require energy for aeration and, in fact, results in a net production of energy from methane formation.

\section{VOLATILE COD LOSSES}

The results obtained from the blank reactor (Figure 7) are somewhat anomalous and no conclusions can be drawn from them. Initially, there was a sharp drop in effluent COD, indicating that volatilization was occurring. However, a sudden rise in $\mathrm{COD}$ was noted beginning midway through the experiment. This corresponds to approximately the time that feed was changed. Falling pH also indicates that volatilization of acidic components was not occurring. The rise in effluent COD between days 11 and 15 is greater than can be accounted for by the feed during this period. This suggests that there was problems with the COD analysis of the effluents. The mercuric chloride added to the reactor may have interfered with the analyses.

Because of the chemical nature of the wet oxidized BGW, some volatilization of organics was expected, especially with the high hydraulic retention times. Unfortunately, the results of this experiment do not allow this to be determined. Obviously, volatilization could not account for a major portion of the COD removal because of the growth of biological solids observed. 


\section{REFERENCES}

APHA, Washington, DC. Standard Methods for the Examination of Water and Wastewater. APHA, Washington, DC.

Bell, N. E. 1981. Treatment of Biomass Gasification Wastewaters Using LiquidLiquid Extraction, PNL-4016, Pacific Northwest Laboratory, Richland, WA.

English, C. J. 1981. Treatment of Biomass Gasification Wastewaters Using Wet Air 0xidation, PNL-4013, Pacific Northwest Laboratory, Richland, WA.

Koa, C. 1980. Extraction of Wastewater from Biomass Gasification. M.S. Thesis, Texas Tech University, Lubbock, TX.

Maxham, J. V., and N. E. Be11. 1980. Treatment of Biomass Gasification Wastewater. Presented at the 11th Biomass Thermochemical Conversion Contractors Meeting, September 23-24, Richland, WA.

Maxham, J. V., and W. Wakamiya. 1980. "Innovative Biological Wastewater Treatment Technologies Applied to the Treatment of Biomass Gasification Wastewater." Presented at the 35th Purdue Industrial Waste Conference, May 13-15, West Lafayette, IN.

Metcalf and Eddy, Inc. 1972. Wastewater Engineering, McGraw-Hi11, New York, NY.

Petty, S. E., S. D. Eliason and M. M. Laegreid. 1981. Treatment of Biomass Gasification Wastewater Using Reverse Osmosis, PNL-4018, Pacific Northwest Laboratory, Richland, WA.

Wakamiya, W., and J. V. Maxham. 1980. "Treatability of Biomass Gasification Wastewater." Presented at the 10th Biomass Thermochemical Conversion Contractors Meeting, February 12-13, Berkeley, CA.

Wakamiya, W., J. V. Maxham and S. E. Petty. 1979. Biomass Gasification Wastewater Treatment - Interim Report, PNL-SA-8165, Pacific Northwest Laboratory, Richland, WA.

45 FR 231. 1980. "Water Quality Criteria Documents; Availability," Federal Register, 45, 231, Friday, November 28, 1980. 
$\underline{\text { DISTRIBUTION }}$

No. of

Copies

OFFSITE

Russ 0'Connell

Biomass Energy Systems Division

U.S. Department of Energy

600 E Street, N.W.

Mail Stop 404

Washington, DC 20545

5 Han Chang

Argonne National Laboratory

Building 362

9700 South Cass Avenue

Argonne, IL 60439

27 DOE Technical

J. V. Maxham

Institute of Paper Chemistry

Appleton, WI 54911

Battelle Columbus Laboratories

S. E. Petty (5)

ONSITE

Richland Operations Office

H. E. Ransom

33 Pacific Northwest Laboratory

D. B. Cearlock

G. W. Dawson

C. J. English (10)

J. S. Fruchter

M. M. Laegreid

E. B. Schwenk

D. S. Sklarew (5)

J. A. Stottlemyre

Publishing Coordination (2)

Technical Information (5)

Geosciences Research and Engineering Laboratory

Distr-1 
1 